\title{
DOES SCHOOLING DECREASE SOCIAL INEQUALITY IN EARLY ACHIEVEMENT?
}

\author{
Passaretta, G.* \& Skopek, J.** \\ * European University Institute, Department of Political and Social Sciences, Italy \\ (giampiero.passaretta@eui.eu) \\ ** Trinity College Dublin, Department of Sociology, Ireland
}

\section{Discussion Paper}

October 11, 2020

\begin{abstract}
Does schooling affect social inequality in educational achievement? Earlier studies based on seasonal comparisons suggested schooling to equalize social gaps in achievement, but recent replication studies gave rise to skepticism about the validity of older findings. We propose an alternative causal design that identifies schooling exposure effects by exploiting (conditionally) random variation in test dates and birth dates for children participating in assessment studies. We test effects of school exposure in first grade for a series of learning domains (vocabulary, grammar, math, and science) by drawing on recent data from the German National Educational Panel Study (NEPS). Findings clearly indicate that schooling increases learning in all domains and particularly in math and science. However, we did not find any evidence that schooling effects differed by children's socio-economic background. We conclude that, while all children benefitted by first-grade exposure, first-grade schooling had no consequences for social inequality in learning. We discuss the relevance of our approach and results in the context of the massive school lockdowns due to the COVID-19 crisis and to further knowledge on the role of schooling in the process of social stratification.
\end{abstract}

Keywords: achievement inequality, social inequality, seasonal comparisons, summer setback, covid-19, schooling 
Acknowledgments: The authors acknowledge funding from the European Union's Horizon 2020 research and innovation program under grant agreement No. 822330 (TECHNEQUALITY). We are grateful to Fabrizio Bernardi, Juho Härkönen, María del Mar Cañizares Espadafor and all other participants of the IWG seminar at the European University Institute for constructive comments and discussion. 


\section{INTRODUCTION}

What is the role of schooling for social inequality in learning? A well rooted tradition of research stresses the role of non-school factors in creating unequal learning outcomes and suggests that schooling, if anything, tends to equalize social inequality in achievement. Proponents of this 'compensatory' view argue that equalization happens because schooling exposes children to more similar environments than the ones they would experience in the outof-school counterfactual, that is the home environments (Downey, von Hippel, \& Broh, 2004; Raudenbush \& Eschmann, 2015). This exact view has fed fears of amplifying social disparities in learning and educational opportunities as a result of worldwide school lockdowns in the wake of the COVID-19 crisis. If the school system reduces inequality, then the absence of schoolbased teaching may foster such disparities in children's learning.

The idea of schooling as equalizer was tested for the first time half a century ago by comparing learning rates across seasons (Heyns, 1978). If test score inequality increases faster over the summer than the school year, then school-factors contribute to the reduction of social inequality in learning. Studies employing the seasonal comparison design (hereafter: SCD) have dominated sociological research on schooling effects for the last 40 years (Alexander, Entwisle, \& Olson, 2007; Downey et al., 2004; Entwisle \& Alexander, 1992; Hayes \& Grether, 1983). Only recently, proponents of the SCD themselves have criticized it for being prone to various statistical artifacts - such as scaling of tests and comparability of test forms - that might have led to an overestimation of schooling's equalizing role (von Hippel \& Hamrock, 2019a; von Hippel, Workman, \& Downey, 2018).

Besides artifacts that may occur as a by-product of repeated testing, the causal validity of the SCD approach hinges on one particularly crucial assumption: the summer is an appropriate counterfactual for the absence of schooling. However, many things may occur during the summer that might be related to differential learning but unrelated to school absence. SCD studies, thus, tend to conflate 'summer' specific factors with more regular out-of-school factors in estimating schooling effects. Furthermore, SCD studies impose high requirements on data such as repeated test score measurements within and across school grades. Outside US, those requirements are rarely met by international or national assessment studies (for some exceptions, see Holtmann, 2017; Verachtert, Van Damme, Onghena, \& Ghesquière, 2009). 
We propose a more parsimonious design for estimating the effect of schooling that is less prone to confounding issues and maybe applicable to a wider set of national assessment data. The proposed design, inspired by previously applied in psychological research on cognitive development (Carlsson, Dahl, Öckert, \& Rooth, 2015; Cliffordson \& Gustafsson, 2008), requires only one assessment per child over the school year and rest on the fact that, in many practical instances, children are not tested at the same time but at different and random time points of the academic year. Exploiting random variation in test dates and the month of birth across children entering school life on the same calendar day, the design identifies the effect that the exposure to the school system has on the achievement of students having the same age at the test day and the social gaps therein.

We apply our design to the case of Germany and focus on the effects of exposure to first-grade schooling. Germany is a country in which early social inequality in achievement matters in particular because Germany's stratified education system tracks students based on their achievement as early as at the age of 10. Previous studies on Germany reported large social gaps in cognitive achievement even before children enter school or right at the school start (Linberg, Schneider, Waldfogel, \& Wang, 2019; Skopek \& Passaretta, 2020). Moreover, such early gaps seem to explain the majority of social gaps in achievement found at the age of transition to secondary schooling (Passaretta et al., 2020). Therefore, studying the contribution of the schooling to the formation of social gaps around first grade is of critical concern in the tracked educational system of Germany. Moreover, Germany provides a theoretically interesting contrast to the case of US predominantly researched previously. Our study employs recent and representative data the German National Educational Panel Study (NEPS). NEPS implemented a comprehensive test program that allowed us to study school exposure effects on various intellectual domains including math, science, grammar, and vocabulary.

Our results show that increased exposure to first-grade schooling improves student learning with respect to all inspected outcomes. However, there is no evidence for those schoolexposure effects to differ by children's socio-economic background. We conclude that firstgrade schooling had no consequences for social inequality in learning.

The paper proceeds as follows. First, we discuss the recent state of schooling research based on the SCD design. Second, we introduce our alternative approach to identify school exposure effects and its potential contribution. Third, we describe data, sampling, variables and the statistical models estimated. Fourth, we present findings and discuss robustness checks. 
Finally, we embed our findings to the state of research and discuss the relevance of our results and approach for the recent challenges posited by the COVID-19 crises and to further knowledge on the role of schooling for social stratification.

\section{PREVIOUS RESEARCH ON THE ROLE OF SCHOOLING FOR ACHIEVEMENT GAPS}

Studying the effect of schooling on social gaps in learning involves comparing outcomes in two states: school versus out-of-school. Since nearly all children in Western societies attend school, in practice, constructing a valid out-of-school counterfactual represents an empirical challenge. The SCD establishes such counterfactual comparison by comparing social gradients in learning rates during the school year - when school is on - versus the summer holiday season - when school is off. The design requires measuring achievement on the same cognitive domain at the beginning and the end of two consecutive school years in order to estimate three seasonal learning rates and the related social gradients (see Figure 1). A central assumption is that while both school and non-school factors shape learning during the school year, non-school factors only influence learning during the summer. This way one can assess the contribution of schooling to learning and to social inequality in learning.

\section{[FIGURE 1]}

Earlier SCD research in the US quite consistently found SES inequality in learning to increase faster in the summer period than the school year (e.g., Entwisle \& Alexander, 1992; Hayes \& Grether, 1983; Heyns, 1978, 1987; Murnane, 1975; Reardon, 2003). Early studies, by now older than 40 years, already suggested that "when it comes to inequality by socioeconomic status, schools are more part of the solution than the problem" (Downey and colleagues 2004, p.616). In the 2000s, a second wave of studies refined the SCD in an attempt to minimize bias arising from non-perfect overlap of test dates with the first and last days of the school years (Burkam, Ready, Lee, \& LoGerfo, 2004; Downey et al., 2004). Notwithstanding, results supported the earlier studies' general conclusion of schooling effectively equalizing social gaps in learning.

The seemingly consistent evidence from SCD research has been contested by a couple of critical replication studies only recently. As von Hippel and Hamrock (2019) uncovered in their study, findings of previous studies were driven by statistical artifacts related to seasonal 
change in the test-forms and non-comparable scaling of test-score data at various measurement occasions. Not all results and conclusions fell, however. When replicating one of the most influential works published by Downey and colleagues (2004) using newer data and properly scaled measures, von Hippel et al. (2018) found that while equalization effects of schooling were generally weak, schools did act as equalizing institutions in the early years of life. The conclusion that schooling in early years can equalize achievement gaps appears reassuring considering the significance of the early years for later achievement and social inequality therein (Heckman \& Cunha, 2007; Passaretta et al., 2020).

Statistical artifacts related to test form and scaling are not the only shortcomings of the SDC. The isolation of school effects in the SCD rests on certain identification assumptions that are extensively discussed in the previous literature (Downey et al., 2004; Downey, Yoon, \& Martin, 2018). Perhaps the most crucial assumption is the absence of schooling being the only reason for the change in learning during the summer. The problem with that assumption may be illustrated well by a parallel stream of literature that examines the effect of schooling on child obesity. The common finding that children's body-mass-index grow faster over the summer than the school year is attributed to compensatory effects of schools' dietary and exercising policies (von Hippel, Powell, Downey, \& Rowland, 2007; von Hippel \& Workman, 2016). Can we maintain that dietary and exercising behavior remain unchanged over seasons? One might argue that summer months are a breeding ground for unhealthy behaviors and BMI would have seasonal change even if school was not absent. For example, summer temperatures may increase ice-cream consumption leading to weight gain among children. Such increase would be unrelated to the absence of schooling per se but happen to occur in the same season. If that is the case, one may provocatively argue that the school effect on BMI growth identified by SCD resembles genuinely an ice-cream effect, at least in part.

The problem is related to omitted variable bias: one cannot rule out that some peculiarities of the summer months having little to share with schools' closure impacted the learning of high and low SES kids differently, thus producing a spurious stronger increase in SES differentials over the summer break compared to the school year. Obviously, the proponents of the SCD are aware of the potential danger of assuming no confounding factors and other important assumptions not mentioned here. At the same time, they posit that those assumptions are less severe compared to the ones implied by more traditional approaches that, 
for example, try to isolate school-effects by controlling for all potential non-school factors (Downey et al., 2018).

\section{AN ALTERNATIVE DESIGN TO IDENTIFY SCHOOLING EFFECTS}

The seasonal comparison of learning rates is not the only possible comparison for studying the effect of school exposure on SES inequality in achievement. An alternative strategy entails contrasting achievement for children who had the exact same age at testing but experienced different amounts of schooling throughout their lives. This contrast is constructed by our design which has its roots in psychological research aimed at identifying the separate contribution of schooling and ageing for the cognitive development (Carlsson et al., 2015; Cliffordson \& Gustafsson, 2008). We specifically focus on the effects of first-grade schooling but, in principle, the proposed design may be extended to measure the exposure effect of later grades.

To be sure, ageing and exposure to schooling are almost perfectly colinear. Our design addresses this issue by exploiting variations in birth dates among children who entered first grade on the same calendar day and the timing of test administration over the school year.

\section{[FIGURE 2]}

Figure 2 illustrates the intuition behind the design. Panel A refers to fictional dates of birth $\left(T_{b}\right)$, school start $\left(T_{s}\right)$, and test administration $\left(T_{t}\right)$ over calendar time. Imagine two children born three months apart but started first grade on the same day - Peter and Simon. By the way the school system is organized, Simon was younger when he started school life. Now imagine both Peter and Simon taking a cognitive test (resulting in a test score Y) on the same calendar day after six months into grade one. In this scenario, we would expect Simon to perform worse than Peter: even though they received the same amount of schooling, Simon was younger and likely at an earlier maturation point at the day of testing. Now imagine a third child - Emily - who entered school together with Peter and Simon. Emily also shares Simon's birthday, which is exactly three months after Peter's. However, for random reasons, Emily took the test exactly three months later in the school year. In this scenario, we would expect Emily to outperform Peter: even if they had equal age at the day of the test, Emily had received more schooling by then. 
Panel B shows the same data over chronological age and makes it apparent that random variation in month of birth and test date, combined with a constant date of school start, allows us to separate the effects of ageing and schooling on learning. Comparing children who differed randomly in age $\left(A_{t}\right)$ but had the same amount of school exposure $\left(E_{t}\right)$ at the test day - that is Peter and Simon - yields information on the effect of age on achievement. Comparing children of the same age at test who randomly had received a different amount of schooling up to the test day - that is Peter and Emily - yields information on the contribution of schooling to achievement. More precisely, in our example, comparing Emily and Peter, who had the same age at the time of testing, provides us with an estimate for the effect of three months difference in school exposure on achievement.

An important insight is that variations in age at test day and school exposure up to the test day depends also on variations in the age at entry into first grade in our design. While we could make sense of Simon's lower performance compared to Peter as a direct consequence of the age difference at testing, Simon was younger at test day because he entered school at a younger age. In the same way, we could make sense of Emily's better performance compared to Peter as a direct consequence of the additional schooling she received. However, Emily received additional schooling by the day of testing because she entered school life at a younger age. Thus, the effect of schooling measured by our design is a composite effect driven by differential exposure to schooling due to differential age at entry. Most school systems feature fixed school entry dates at the national or regional level combined with cut-off rules that lead to age-variations among children entering first grade on the same calendar day. Thus, taking into account such age at entry effects is essential to evaluate the effects of exposure to the school system. Moreover, one of the most straightforward real-world policies to increase school exposure in the early years is, indeed, adding schooling before primary school starts. Our design is therefore particularly relevant for the debate over the effect of policies increasing the early exposure to formal teaching in the classroom by lowering the school entry age.

\section{A FORMAL APPROACH}

We can express the relationships more formally by the following theoretical model

$$
y=\beta_{0}+\beta_{1} E_{t}+\beta_{2} A_{t}
$$


with $y$ denoting student's expected achievement, $E_{t}$ denoting the exposure to the school year up to the test date, and $A_{t}$ denoting age at test date. Age at test date is the difference between test date $\left(T_{t}\right)$ and birth date $\left(T_{b}\right)$. In most assessment data, school exposure can be measured by the time difference between the test date $\left(T_{t}\right)$ and the starting date of school $\left(T_{s}\right)$.

To see why exposure coefficient $\beta_{1}$ (and also age coefficient $\beta_{2}$ ) measure a composite effect, we can write out a theoretical model in which age at test day $\left(A_{t}\right)$, age at entry $\left(A_{s}\right)$, and school-year exposure $\left(E_{t}\right)$ have separate effects on achievement (see Cornelissen \& Dustman 2019):

$$
y=\lambda_{0}+\lambda_{1} E_{t}+\lambda_{2} A_{t}+\lambda_{3} A_{s}
$$

Since $E_{t}=T_{t}-T_{s}, A_{t}=T_{t}-T_{b}$, and $A_{s}=T_{s}-T_{b}$, it follows logically that $A_{s}=$ $A_{t}-E_{t}$. Replacing $A_{s}$ and rearranging terms in Eq. 2 leads to

$$
\begin{gathered}
y=\lambda_{0}+\lambda_{1} E_{t}+\lambda_{2} A_{t}+\lambda_{3}\left(A_{t}-E_{t}\right) \\
=\lambda_{0}+\left(\lambda_{1}-\lambda_{3}\right) E_{t}+\left(\lambda_{2}+\lambda_{3}\right) A_{t}
\end{gathered}
$$

which demonstrates the composite nature of the school exposure effect measure $\beta_{1}=$ $\lambda_{1}-\lambda_{3}$ (as well as the age at test date effect measured by $\beta_{2}=\lambda_{2}+\lambda_{3}$ ).

Considering achievement scores of a population of students who have the same age at test $\left(A_{t}\right)$, parameter $\beta_{1}$ identifies the expected marginal gain in achievement for the average individual if she had received more exposure to the school year, which in practice would have been feasible only by starting school earlier. Hence, $\beta_{1}$ reflects exactly the effect of increasing exposure to first grade $\left(\lambda_{1}\right)$ obtained by starting school earlier in life $\left(-\lambda_{3}\right)$. We deliberately conceive age of entry effects as a constituent part of the effects of schooling as they occur in an actual school system characterized by institutional rules of enrolment that features age variations among children starting school on the same calendar day.

To identify the model in Eq. 1 in practical applications, we need sufficient variation in at least two out the three terms: test dates $T_{t}$, dates of school year start $T_{s}$, and birth dates $T_{b}$. In our empirical case, Germany, we will exploit predominantly variations in test dates and birth dates since school start is legally fixed and equal for all children (within states). If school start is fixed (i.e., $T_{s}$ is a constant) and if test dates $\left(T_{t}\right)$ and birth dates $\left(T_{b}\right)$ are independent to 
observed and unobserved factors predicting achievement, then age at testing $\left(A_{t}=T_{t}-T_{b}\right)$ and school exposure $\left(E_{t}=T_{t}-T_{s}\right)$ are independent of those factors too. If these conditions are met, then our parameter of interest, composite effect $\beta_{1}$, can be estimated absent of selection bias.

The ultimate aim of our analysis is testing whether and how socioeconomic status (SES) gaps in children achievement vary with school exposure effects. We are interested to test if parameter $\beta_{1}$ is a function of socioeconomic status of the family, which can be expressed by extending Eq. 1 to include SES and the multiplicative terms with school exposure and age at test. After rearranging terms, we can write

$$
y=\beta_{0}+\left(\beta_{1}+\beta_{4} \cdot S E S\right) E_{t}+\left(\beta_{2}+\beta_{5} \cdot S E S\right) A_{t}+\beta_{3} \cdot S E S
$$

From Eq. 4 we can derive three theoretical scenarios regarding the impact of school exposure on achievement inequality by family SES. If $\beta_{4}<0$, school exposure had an equalizing effect on SES related inequality in achievement. If $\beta_{4}=0$, then school exposure had no effect on social achievement inequality (2). Finally, if $\beta_{4}>0$, school exposure would exacerbate achievement inequality. Note that also parameter $\beta_{4}$ captures the composite effect of differential school exposure achieved by manipulating school entry age (for a formal demonstration see Appendix A). The methods part will provide more details on the precise estimation of the theoretical models described by Eq. 1 and 4 in the context of our data.

\section{THE CONTRIBUTION TO A SOCIOLOGICAL PERSPECTIVE ON SCHOOLING}

Starting school life at a younger age is one way to increase the time spent in school. Longer school days, fewer holidays within the academic term, and school-year extensions into the summer or the winter break are feasible alternatives for policy making. However, there is no guarantee that different ways of extending school exposure would be equally effective in terms of fostering learning and mitigating social gaps therein. Schooling effects depend on out-ofschool counterfactuals (Raudenbush \& Eschmann, 2015) and these counterfactuals may vary depending on age and life stage, season, or even time of the day.

Similar to the SCD, our design considers the impact of school-year exposure rather than instructional time measured by school days or teaching hours within the academic term (e.g., (Carlsson et al., 2015; Cliffordson \& Gustafsson, 2008). Both approaches see schools as more 
than simple providers of instructional time in the classroom, a conceptualization of schooling frequently found in economic perspectives that quantify school exposure by counting school and out-of-school days (Carlsson, Dahl, Öckert, \& Rooth, 2015; Cliffordson \& Gustafsson, 2008). After all, children are exposed to the school system as an institution even during nonschool days within the academic term (for example, when children do homework at home).

By adopting a similar institutional perspective on the role of schools, our approach provides a viable complement to the SCD. Comparing social inequalities in learning rates within the school years and the summer months provides an estimate for the impact of extending the school year into the summer. One may rise doubts if increasing overall school year exposure, in our case by starting school life earlier, would yield the same result. Hence, our design complements the SCD insofar as it provides an estimate for the effect of school exposure as manipulated by starting school life earlier. Thus, both designs may yield different findings to the extent that different ways of manipulating school exposure (school at younger ages vs. smaller summer school gap) may generate different results. However, a substantive interpretation of the differences in the effects of manipulating school exposure via earlier entries or shorter summer breaks is rendered difficult by potential statistical artifacts and confounding issues related to the seasonal comparison of learning rates. Compared to SCD, our design is less prone to confounding and has the advantage of identifying a causal effect based on one achievement measure only, which reduces data requirements and the risk of statistical artifacts.

\section{DATA AND METHODS}

\section{DATA}

For studying the effect of schooling on early achievement in Germany we employed nationally representative data from the Kindergarten Cohort of the German National Educational Panel Study (hereafter: NEPS). The Kindergarten Cohort covers a sample of children enrolled in Kindergarten in the years in 2010/2011, around the age of four to five. In Germany, school starts formally with the first grade of primary school (grade one to four) at around six to seven years of age. Unlike other countries, Kindergarten is not part of the formal education system although it has more than 90 per cent attendance rate.

The sample has been followed to the end of primary education (grade 4) and early secondary education (grade level 5 and 6). Children were tested in various domains but only 
once in each grade. The original sample $(\mathrm{N}=2,996)$ was augmented by a refreshment sample of 6,341 children in Wave 3 (2012), which is the point marking the transition from Kindergarten to primary education (grade 1 ).

For the purpose of our article, that is studying the effect of first-grade school exposure, we drew upon grade one data only (Wave 3). ${ }^{1}$ We selected first graders in the refreshment sample only because the original Kindergarten sample suffered from strong attrition between the last year of Kindergarten and grade one (approximately $85 \%$ attrition). The refreshment did not suffer from any attrition because it was sampled precisely in grade one (Wave 3, school year 2012/2013). Data collection involved child testing, parent interviews, and teacher and school headmaster questionnaires. Children were tested in school. There were two test booklets, one containing math and science tests and the other vocabulary and grammar tests. Testing took place in two test days in each school and students worked on one test booklet per test day. ${ }^{2}$ Schools were randomly assigned to two different time windows for testing: mid of February till mid of April in 2013 versus mid of May till mid of June in 2013. Thus, testing commenced after the winter break and ceased before the summer break, when children had already been into first grade for a minimum of 5-6 months (February) and a maximum of 10 months (June). The variation in school exposure imposed by variation in testing dates, around slightly less than 6 months of primary schooling, is almost doubled compared to the period of school closure exploited by the SCD (3 summer months approximately). Although within the assigned time window schools might have had some discretion in choosing the exact two days of testing, the overall procedure ensured that the timing of children's testing is random. In fact, as we will show later, neither parental SES nor school characteristics predict the day of testing. Parents of participating children were surveyed via telephone interview. Only one reporting parent (or the custodian in few cases) was selected for interview.

\footnotetext{
${ }^{1}$ While our design allowed the identification of the effects of exposure to later grades (for example, the exposure to second or third grade), the latter effects are confounded by summer holidays and hinges on treatments whose relevance decreases over grades relative to the overall exposure to schooling. Such effects also have different theoretical meaning and dubitable policy implications, since they hinge on a composite treatment hardly manipulated by real world policies, that is the differential exposure to second or third grade due to an earlier start into first grade.

${ }^{2}$ Test booklets were rotated across test days and students randomly assigned to those different test groups.
} 


\section{SAMPLE SELECTION}

We selected children from the refreshment sample who participated at school testing and whose parents participated in the interview (see Table 1 for sample selection logic). After list-wise deletion of missing values on analytical variables, the sample included 5,481 children.

\section{[TABLE 1]}

In general, mandatory schooling in Germany ('Vollzeitschulpflicht') commences in the calendar year children turn six if age six is reached before a certain cut-off date. If they turn six after the cut-off in that year, school enrolment happens in the subsequent year. Due to the federal autonomy in German education, the exact cut-off date varies from end of June to end of September between German federal states and so does also the exact day of school start (see Table 2). Cut-off dates are fixed within federal states. School start dates are also fixed within states but do vary across academic years.

For example, in Bavaria, children born in September 2006 had to enter school on September 13, 2012 (school year 2012/2013) because they reached the age of six before the cut-off date (end of September). Children born a year before, in September 2005, however, were scheduled to enter school in 2011 (school year 2011/2012). Finally, children born in October 2006 were scheduled to enter school in 2013 (school year 2013/2014). Parents can apply (but not choose) for deferring or anticipating enrolment by one year but there is no guarantee of success. Postponement is more regulated than anticipation and usually occurs only if children had examined to be physiologically, psychologically, or socio-emotionally unfit for school. In practice, applications for both anticipation and postponements occur only when children's age at the cut-off date is close to the threshold. Nevertheless, an overwhelming majority of children has regular school enrolments. According to the German national education report for school year 2012/2013, about $10 \%$ of all school enrolments had been irregular enrolments with about 7\% postponed and 3\% anticipated enrolments (Bildungsbericht 2014).

Based on the cut-off dates, we derived the legally defined birth ranges corresponding to a compliant school enrolment in the academic year 2012/13 in each of the German Laender. For example, in Bavaria, all children born between October 2005 and November 2006 were in the 'right' age range at the cut-off date and should have entered primary school on September 
13, 2012. ${ }^{3}$ Table 2 provides Laender details on the cut-off dates, school start dates, and the birth ranges corresponding to a compliant school entry. Around $13 \%$ of the children in our sample were outside the right birth ranges and must have entered first grade in the fall of the previous (2011 or before) or the following years (2013 or after). Such unregular - early or late - school enrolment is likely to be associated with factors influencing achievement in school (such as children's developmental stage or general school readiness). We excluded those non-compliers from the analyses because selectivity in age at entry would cause selectivity in school exposure. Thus, our estimation is based on compliers, i.e. first-grade children in the academic year 2012/13 who had a regular school enrolment.

The sample of compliers (Sample A, N=4,759) included only children whose age at school entry is defined entirely by the enrolment rules. We know from previous research that, in practice, it is those children who are just at or close to the upper and lower limits of the 'right' birth range at the cut-off date who are most likely to apply for anticipation or postponement (Mühlenweg \& Puhani, 2010). For example, in Bavaria, a child aged exactly 6 at the cut-off date (born on September 2006) had the choice to apply for a postponed enrollment in 2013/14 and be among the oldest rather than the youngest in the classroom. Conversely, a child aged exactly 6 years and 11 months at the cut-off date (born on October 2005) was only one month below the threshold age at the previous year's cut-off and might have applied for anticipated enrollment in 2011/12 and be the youngest rather than the oldest in the classroom. Compliers with the choice to apply for anticipation or deferral might be selective in terms of unobservable characteristics related to achievement and their parents may have adopted strategic behaviors aimed at leveraging the school entry age (resulting in endogenous exposure to grade one in our setting).

To assess how robust our findings are against potential selectivity of those cases, we constructed alternative and stricter samples that removed from Sample A potential compliers with the choice to apply for anticipation or deferral in progressive steps. First, Sample B excluded children who were exactly at the lower (6 years) and upper limit (6 and 11 months) of the 'right' age range at the cut-off date $(\mathrm{N}=4,042)$. For example, in Bavaria, Sample B excludes children born in October 2005 and September 2006. Second, Sample C excluded additionally those children who were up to one month above (6 and 1 month) or below ( 6 and

\footnotetext{
${ }^{3}$ In absence of detailed information on birthdays, we assumed all children were born the $15^{\text {th }}$ of the month $\left(14^{\text {th }}\right.$ in February) as to minimize error.
} 
10 months $)$ the limits $(\mathrm{N}=3,265)$. Thus, Sample $\mathrm{C}$ is the strictest of all three samples. It aims at including only compliers without choice to apply for anticipation or deferral (i.e., the population of children for whom either anticipation or postponement of school entry is nearly absent). Sizes of the three samples vary slightly by outcome as we aimed at maximizing sample size for each outcome (see Table 3).

[TABLE 2]

\section{COGNITIVE OUTCOMES}

We focus on a set of four complementary cognitive domains along the full spectrum of the fundamental skills thought in primary school: vocabulary, grammar, math, and science. Math, science, and grammar tests were scaled based on item-response theory (IRT) models which provide interval scaled scores (WLE scores) best representing children's abilities (Pohl and Carstensen 2012). For vocabulary, the NEPS data provided only a sum score. A recent article pointed out that sum scores are responsible for longitudinal artifacts that have plagued seminal findings in the SCD literature so far, and suggested IRT scaled tests as superior alternatives (von Hippel \& Hamrock, 2019). However, our study is not affected by scaling artifacts since we mostly employ IRT-scaled tests and do not compare test scores over time.

Table 3 describes test scores variables in original metrics. For our analyses, we zstandardized test scores for all four domains in each of the samples to have a common mean of zero and unit standard deviation. Test score reliability was documented to be at .72 and .74 for math and science respectively. Imperfect reliability inflates test score variance which can lead to an attenuation bias in estimates for the effects of SES and schooling on z-scores. Thus, whenever possible, we adjusted test scores for reliability as suggested in Reardon (2011). We comment on both the unadjusted and, whenever possible, the adjusted results.

[TABLE 3] 


\section{SCHOOL EXPOSURE AND AGE AT TESTING}

Exposure to first-grade schooling is exogenous only if test dates are independent of SES and other factors influencing achievement (since $E_{t}=T_{t}-T_{s}$ with $T_{s}$ being a constant for students from the same federal state). Test dates ${ }^{4}$ should fulfill such requirements by design as schools were assigned testing periods and neither first-grade students nor their parents had any influence on the timing of tests. We can be confident about exogeneity in test dates if test dates are not predicted by parental SES or school characteristics. Table 4 shows results from regression models that attempted to predict birth and test dates based on parental SES and class level characteristics. Results clearly show that, within federal states, test dates were not predicted by SES nor a wide array of characteristics relating to the social, cognitive, and noncognitive composition of the classrooms and the classroom quality and conditions. ${ }^{5}$ The independence between tests dates and class characteristics is particularly reassuring because, although assigned to the testing periods, schools might have had some discretion in choosing the exact dates of testing.

In addition to random tests dates, the exogeneity of age at the day of testing also requires birth dates to be independent of SES and other factors influencing achievement (since $A_{t}=$ $T_{t}-T_{b}$ ). Birth dates should be exogenous in our samples because we only selected compliers with the enrolment rules implemented in each federal state. Table 4 shows that this has been largely the case in our three samples, with the partial exception of parental SES in the overall sample of compliers (Sample A). However, the SES-birth date association is trivial and, as expected, even disappears when moving to the more restrictive samples of compliers without the choice to apply for anticipation or deferral (Sample B and C).

Altogether, selectivity analyses in Table 4 make us confident that, within federal states, children in our samples randomly differed in school entry age, which resulted in random variation in age at test and exposure to first-grade schooling. Interestingly, this was the case even in the overall sample of compliers (Sample A) for which we might have expected some SES-related age differences at school entry, possibly due to parental strategic behavior. Thus,

\footnotetext{
${ }^{4}$ In absence of information on the exact day of testing, we assumed testing took place the 15th of the month (14th on February) as to minimize error.

${ }^{5}$ While children tested in the same school may sat in different classrooms, variability across classrooms largely resembles variability across schools in the NEPS.
} 
we mainly comment on the results for sample A but also report findings for more restrictive samples of compliers without choice to apply for anticipation or deferral (Samples B and C).

\section{[TABLE 4]}

\section{SOCIOECONOMIC STATUS OF THE FAMILY}

We used the highest parental education and occupational status as proxies for family SES. In Germany, educational attainment is usually preceding childbirth and comparably stable over the life course. Occupational status, in contrast, is subject to more fluctuations and also more prone to measurement error. Thus, we preferred parental education as our primary SES indicator. We constructed highest parental education by the number of years necessary to attain the highest educational certificate among the parents (variables for single parents are generated by NEPS, see Skopek and Munz 2016). Occupational status of parents is measured by the highest ISEI among parents (Ganzeboom \& Treiman, 1996). Both information was provided by the parent interviews in Wave 3. We report the main analyses for parental education but results using parental ISEI were very similar and available in Supplementary Figure C1. Henceforth, we use parental education and SES synonymously. Descriptive statistics for all variables used in the main analyses are shown in Table 3.

\section{MODELLING APPROACH}

Our modelling involves regressing the test scores on school exposure while accounting for gender, age at test and state fixed effects. The baseline estimation model resembles Eq. 1 in the theory part:

$$
z_{i f}=a_{0}+a_{1} E_{\text {Tif }}+a_{2} A_{\text {Tif }}+a_{3} S E S_{i f}+a_{4} G E N D E R_{i f}+m_{f}+e_{i f}
$$

where the z-standardized test score of the individual $i$ in federal state $f$ is regressed on gender, parental SES, age at testing $\left(A_{T}\right)$ and the exposure to first-grade schooling up to the testing $\left(E_{T}\right)$. In addition, the estimation model includes fixed effects for German federal states $\left(m_{f}\right)$. $E_{T}$ is random only when children are subjected to the same enrolment rules. Hence, accounting 
for state effects is necessary as both cut-off dates and school start dates vary across German Laender.

Our main interest lies in studying if SES gaps in achievement increase with exposure to first grade (keeping age at test constant). Modelling interaction terms in accordance with the theoretical model described by Eq. 4 provides a direct test for this idea:

$$
\begin{gathered}
z_{i f}=b_{0}+b_{1} E_{\text {Tif }}+b_{2} A_{\text {Tif }}+b_{3} S E S_{i f}+b_{4} G E N D E R_{i f}+b_{5} E_{\text {Tif }} S E S_{i f} \\
+b_{6} A_{T i f} S E S_{i f}+m_{f}+e_{i f}
\end{gathered}
$$

Equation 5 and 6 were estimated separately for each of the four standardized competence measures in all three analytical samples (A, B, and C). Variable measuring age at test day, school exposure at test day and SES are centered in each of the subsamples to ease the interpretation. Although we did not expect heterogeneity in schooling effects between boys and girls, estimating (5) and (6) for boys and girls separately put our design to a further test. As a result, for the main analyses we estimated 108 models for each of the two SES measures. Furthermore, we run a series of additional and alternative models to ensure the robustness of our findings. All analyses employed design weights provided by the NEPS.

\section{RESULTS}

Table 5 summarizes the main estimates of our analysis obtained for Sample A. The baseline model (Eq. 5) estimated the main effects of school exposure, age, and years of parental education (noted by SES) while controlling for gender and federal state differences (fixed effects). In line with the previous studies on achievement gaps, our results show substantial SES-gaps among children right at the school start. Coefficients of .15-.20 imply a maximum gap of 2 standard deviations (SD) across the entire range of parental education (10 years of parental education). The gap seems somewhat lower in math (.15) compared to grammar (.18), vocabulary (.18), and science (.17). As expected, reliability-adjusted math and science scores show somewhat larger gaps. Overall, SES effects on scores are substantial and, despite minor differences, pretty consistent across all domains. To facilitate interpretation, these SEScoefficients are plotted in the upper panel of Figure 3 (Columns A), which also provides coefficient plots based on the more restrictive Samples B and C for comparison (compliers without choice to apply for anticipation or deferral). 
[TABLE 5]

Table 5 also provides clear evidence for the positive effects of school exposure and age at test on child achievement. School effects are statistically significant across the board. Notably, schooling exposure has larger effects on math and science than on vocabulary and grammar. For example, one additional month of schooling increases math scores by about $12 \%$ of a SD ( $14 \%$ for reliability adjusted scores) whereas it increases vocabulary scores only by $3 \%$ of a SD (see Table 5, Eq.5). In contrast to schooling effects, age effects are somewhat more consistent across domains and comparably small (in the case of math and science): one month of age is associated with 3 to 5\% of a SD higher scores. Age and school effects are similar for vocabulary and grammar. Note that our approach implies both school and age effects to add up on children's growth in cognitive development and learning. For example, based on our estimates, after 10 months of being in first grade an average child's vocabulary score is expected to increase by $73 \%$ of a standard deviation, and more than one third of that increase is explained by the exposure to schooling. The equivalent for math was a score growth by 1.6 SDs with schooling explaining three fourth of it. Figure 3 (upper panel, Column B) shows that schooling effects were statistically identical for the more restrictive samples of compliers (Samples B and C). Age effects were also similar in the more restrictive samples of compliers (see supplementary Figure C2).

Can test scale differences (sum scores vs. IRT scales) explain our findings of domainspecific school exposure effects? We believe this scenario is unlikely. Vocabulary and grammar - both sub-dimensions of German language competency - differ in test scaling but we find age and school effects being similar for both domains. Moreover, age effects are similar across different domains and different test scales. If scaling was fully responsible for the patterns of results across domains, it would have been extremely unlikely to find similar age and schooling effects for vocabulary and grammar and similar age effects in all domains. Finally, schooling effects on grammar are substantially lower than math and science even though all three tests were IRT scaled.

Having ruled out methodical artifacts, we can at this point only speculate on substantive explanations for why we find comparably smaller schooling effects on language-related domains. Like math and science contents, vocabulary and grammar training form part of the 
curriculum in first-grade primary school (subject "Deutsch" in which children also learn to read and write). However, since language development is a generally robust process that happens very early in life (Shonkoff \& Phillips, 2000), it might be possible that language skills are less malleable through instruction in school at later ages. Saturation effects may also play a role since language competencies are acquired long before school while more technical skills of math and science are typically learned in school. Furthermore, peer-group mechanisms (Justice, Petscher, Schatschneider, \& Mashburn, 2011) and school segregation along social lines - and thus indirectly school and classroom segregation by prior language skills - could also explain weaker schooling effects on language. Whereas further research may address those specific questions, our findings do underline the importance of differentiating learning domains when examining schooling effects.

Our main purpose was to test if schooling effects differed by parental SES. Table 5 provides results on our models that included interaction terms (see Eq. 6). Figure 3 (upper panel, Column C) visualizes interaction coefficients between school exposure and SES (interaction coefficients between age and SES are shown in Supplementary Figure C2). Results regarding the SES-schooling interaction are clear-cut; there are no signs of any meaningful interaction effect for any domain, implying that schooling effects do not vary by parental SES. In other words, exposure to first-year schooling does not seem to modify any of the SES gaps found in the various domains, thus suggesting that all children - regardless of their parental background - benefit from schooling alike. When it comes to the SES-age interaction we find mixed evidence (see Table 5 and Supplementary Figure C2); while not being statistically significant at conventional levels for vocabulary, grammar, and math, age effects do depend on SES for science. Estimates in Table 5 imply, for example, that the unadjusted SES gap in science between children differing in four years of parental education would have grown from approximately 69 to $97 \%$ of a SD over a 10-months period and independent of school exposure. Hence, SES gaps in science might be growing over first grade, but this seems due to factors related to ageing and not school exposure itself. Estimates for the stricter samples of compliers are almost identical (Samples B and C).

We run all analyses using parental ISEI as measure for SES. Results are nearly identical to the ones reported here (see Supplementary Figure C1). We also tested for gender differences in the effects by running our models for boys and girls separately (middle and lower panels of Figure 3). In short, we could not detect meaningful differences in the inspected relationships 
by gender. Although there was somewhat more uncertainty about the presence of schooling effects on grammar and vocabulary in those separated samples, our general conclusions about the absence of school exposure effects on SES-inequality apply to boys and girls equally. All in all, our results clearly suggest that first-grade schooling did not reduce or increase SESinequality in educational achievement. Exposure to schooling seems to improve educational achievement in all skill domains but not to have any impact on SES-related inequalities in any of those domains.

\section{[FIGURE 3]}

\section{FURTHER ROBUSTNESS ANALYSES}

We ran additional analyses to ensure the robustness of our findings. First of all, we estimated Eq. 5 and 6 including an indicator for migration background among the covariates (at least one parent not born in Germany) and, when relevant, also the multiplicative terms between the migration indicator and school exposure and age at test, respectively. While being more consumptive, these augmented models may reflect sharper theoretical measures for SES inequalities as migrant families are usually overrepresented in the low tail of SES distribution. Results from the augmented models fully confirm our general conclusions (see Supplementary Figure D1 and D2 for parental education and parental ISEI respectively). As expected, SES gradients in achievement are somewhat lower compared Figure 3, but those social inequalities are still astoundingly strong and unchanged by school exposure.

We additionally estimated Eq. 5 by grouping children in three (state-specific) groups which are equally spaced in terms of their age of entry into first grade (specifying entry age in a linear fashion would be inestimable, as discussed in the theoretical part). The estimation of school exposure effects in the augmented models hinges on the comparison among children with reduced variations in their entry age. On the downside, this strategy also dramatically reduces variation in school exposure by construction, thus representing a strict test for our design. Analogously, we added entry age dummies and their interactions terms with school exposure and age at entry to Eq. 6. Adding entry age dummies increases uncertainty around the estimates of school exposure effects, reduce slightly their magnitude, but leave interaction terms with SES unchanged (see Supplementary Figure D3 and D4 for parental education and 
parental ISEI respectively). Hence, our general findings are supported by the data even when reducing variations in school entry age and, therefore, exposure to first-grade schooling.

\section{CONCLUSIONS}

Decades of research has suggested that schooling acts as an institution ameliorating social inequality in learning. Learning in home environments is so heavily dependent on the socioeconomic position of the parents that even unequal school systems contribute to equalization. These ideas have mainly arisen from the observation that social gaps in achievement grow faster during the summer break - when schools are closed - compared to the school year.

But does schooling actually reduce social inequality in educational achievements? This article answered this question looking at the role of first-grade schooling in the German context education. The equalizing potential of schools in the early years of life is crucial in all institutional contexts but particularly in Germany, where most of the social differences in achievement contributing to track allocation at age 10 are produced right at the school start. If first-grade schooling reduced those early inequalities, such equalization effect would foster fairness in the track allocation process and contribute to equalization in later life chances.

We proposed a design to identify causal effects of school exposure that exploits random variation of birth dates of children entering school on the same calendar day and test dates in assessment studies. Notably, the proposed design complements the predominant seasonal comparison design which has been used in the US literature on schooling effects. In contrast, our design is less data consumptive by requiring only one instead of four points of skill measurement at the minimum. We applied this design to most recent educational data from the German National Educational Panel Study and studied school exposure effects on first-grade students.

Our findings on the impact of schooling on achievement inequality are clear-cut: We found no effect of first-grade schooling on social gaps in achievement in a series of skill domains. Gaps in achievement between children from higher versus lower social backgrounds were the same irrespective of the time they had been exposed to first-grade schooling. Even though we found clear evidence for schooling to facilitate learning, our study could not find any evidence that it does so at different rates for children of different social backgrounds. Thus, we conclude that schooling in Germany neither equalizes nor exacerbates social inequality in 
achievement, at least in the first grade. One can argue schooling is beneficial for all children at comparable rates.

This article challenges older findings from seasonal comparisons studies that found equalizing effects of schooling in the US and other European countries and accord with more recent accounts that questioned those earlier findings based on methodological shortcomings (von Hippel \& Hamrock, 2019b; von Hippel et al., 2018).

We would like to stress that our results do not necessarily stand in contrast with the seasonal comparison literature. One possibility is that extending first-grade schooling by anticipating school life bears no consequences for social inequality in achievement while extending first grade into the summer break may indeed ameliorate such inequalities. It is difficult to assess whether such a scenario is likely, however. We are left to wonder whether the common findings in seasonal comparison research relates to the absence of schooling or other things happening over the summer that are not at all related to the school closure. For example, favorable weather conditions in the summer make contacts with friends in the neighborhood more likely even outside school hours, and those interactions may well be consequential for differential learning by social background. Such potential seasonal 'neighborhood effects' - not caused by but associated to the school absence - could sneak into 'schooling effects' identified by the seasonal design. While von Hippel \& Hamrock (2019) recently put into question the previous empirical evidence based on potential artifacts due to scaling and changing test form, they still reason within a seasonal framework suffering from potential omitted variable bias, and still find an equalizing effect of schools in the early years of life. Confounding issues, together with issues of scaling and changing test form that affects longitudinal comparisons, are eliminated in our design. Furthermore, by its parsimony in terms of data requirements, our design may facilitate cross-national research on schooling effects which could address the important question of whether and to which extent schooling effects might be shaped by features of the larger macro context of countries and education systems.

A first naïve look at our findings may shed hopes on the consequences of school closures in the midst of the current COVID-19 pandemic. If schools do not impact inequality, we may expect school closure under COVID-19 to slower learning of children from different social background equally. However, the current crisis resulted in a peculiar out-of-school counterfactual. In many countries, the pandemic kicked in right at the middle of the school year 2019/20 and teaching continued remotely and online, and in many cases through the direct 
involvement of the parents. It is unclear how such a peculiar situation of school absence matches with the counterfactuals as constructed by the seasonal comparison design and our design. Summer often coincides with holidays and parents are not necessarily focused on building up their children's curricula during holidays (Von Hippel, 2020). After all, parents outsource most of the teaching to schools and those schools will soon reopen their doors. Early years of life are an unexpected analogy: while not on vacation, parents usually do not rush children's learning right before the school start precisely because the school will soon start. The spreading fear is that school closures under COVID-19 will indeed sharpen social differences in learning as parents acted as home teachers whose effectiveness is likely to change across social strata. Furthermore, remote teaching comes at the disadvantage of those with limited access to broadbands and technological devices. Reliable data to assess the consequence of school closure under the COVID-19 pandemic is not yet available but we agree with other colleagues that the prospects are not encouraging (Defeyter et al., 2020; von Hippel, 2020). Social scientists will find ways to assess the consequence of COVID-19 for SES-inequality in achievement but the extent to which such consequences will relate to school closures per se is rather unclear. Even if future research will succeed in isolating school closure effects from other COVID-19 related factors, such effects would refer to a very peculiar out-of-school counterfactual that does not reflect life in non-pandemic historical periods. Hence, COVID-19 based designs will not be perfect when it comes to assess the effects of schooling under normal circumstances as much as our design is not perfect when it comes to assessing schooling effects under COVID-19.

We believe our results may help to reframe the way sociologists and policy makers think of schooling as an institution fostering equity and helping children from socioeconomically disadvantaged backgrounds to catch up with their more advantaged peers. The Coleman report in the early 60s stressed the greater importance of non-school factors compared to school factors in shaping social inequality in learning. Starting from the 60s, seasonal designs have substantiated such perspective and repeatedly argued that, "when it comes to inequality by socioeconomic status, schools are more part of the solution than the problem" (Downey and colleagues 2004, p.616). Most recent studies have already brought up skepticism towards those earlier assertions. Our study substantiates such skepticism and challenges over-optimistic ideas about schooling as being a social 'equalizer'; rather we point to the possibility that schooling might be wholly agnostic when it comes to social inequality in achievement. Thus, we might 
re-address the issue by arguing that, when it comes to inequality by socioeconomic family background, schools are likely neither the problem nor part of the solution - at least when it comes to the first year of schooling. 


\section{REFERENCES}

Alexander, K. L., Entwisle, D. R., \& Olson, L. S. (2007). Lasting consequences of the summerlLearning gap. American Sociological Review, 72(2), 167-180.

Bildungsbericht (2014). Bildung in Deutschland 2014 [National Education Report 2014]. Autorengruppe Bildungsberichterstattung. Bielefeld: Bertelsmann.

Bradbury, B., Corak, M., Waldfogel, J., \& Washbrook, E. (2015). Too many children left behind. The U.S. achievement gap in comparative perspective. New York: Russel Sage Foundation.

Burkam, D. T., Ready, D. D., Lee, V. E., \& LoGerfo, L. F. (2004). Social-Class Differences in Summer Learning Between Kindergarten and First Grade: Model Specification and Estimation. Sociology of Education, 77, 1-31.

Carlsson, M., Dahl, G. B., Öckert, B., \& Rooth, D.-O. (2015). The effect of schooling on cognitive skills. The Review of Economics and Statistics, 97(3), 533-547.

Cliffordson, C., \& Gustafsson, J. E. (2008). Effects of age and schooling on intellectual performance: Estimates obtained from analysis of continuous variation in age and length of schooling. Intelligence, 36(2), 143-152.

Defeyter, M. A., von Hippel, P. T., Shinwell, J., Mann, E., Henderson, E., Brownlee, I., DalySmith, A. (2020). Written evidence submitted by Professor Greta Defeyter Covid-19: Back to School, Rebuilding a Better Future for All Children Covid-19 and School "Closures" (Working Paper).

Downey, D. B., von Hippel, P. T., \& Broh, B. A. (2004). Are Schools the Great Equalizer? Cognitive Inequality during the Summer Months and the School Year. American Sociological Review, 69(5), 613-635.

Downey, D. B., Yoon, A., \& Martin, E. (2018). Seasonal, Schools and Inequality: Implications from Research, Comparison. In B. Schneider (Ed.), Handbook of the Sociology of Education in the 21st Century (pp. 55-69). Swizerland: Cham: Springer.

Entwisle, D. R., \& Alexander, K. L. (1992). Summer Setback: Race, Poverty, School Composition and Math Achievement in the First Two Years of School. American Sociological Review, 57, 72-84.

Ganzeboom, H. B., \& Treiman, D. J. (1996). Internationally comparable measures of occupational status for the 1988 International Standard Classification of Occupations.". 
Social Science Research, 25(3), 201-239.

Hayes, D. P., \& Grether, J. (1983). The school year and vacations: When do students learn? Cornell Journal of Social Relations, 17, 56-71.

Heckman, J. J., \& Cunha, F. (2007). The Technology of Skill Formation. The American Economic Review, 97(2), 31-47.

Heyns, B. (1978). Summer learning and the effects of schooling. New York: Academic.

Heyns, B. (1987). School and cognitive development: Is there a season for learning? Child Development, 58, 1151-1160.

Holtmann, A. C. (2017). Why are children from disadvantaged families left behind?

Justice, L. M., Petscher, Y., Schatschneider, C., \& Mashburn, A. (2011). Peer Effects in Preschool Classrooms: Is Children's Language Growth Associated With Their Classmates' Skills? Child Development, 82(6), 1768-1777.

Murnane, R. J. (1975). The Impact of School Resources on the Learning of Inner City Children. Cambridge, MA: Ballinger.

Mühlenweg, A. M., \& Puhani, P. A. (2010). The evolution of the school-entry age effect in a school tracking system. Journal of Human Resources, 45(2), 407-438.

Passaretta, G., Skopek, J., \& Huizen, T. Van. (2020). To what extent is social inequality in school-age achievement determined before and during schooling? A longitudinal analysis in three European countries. SocArXiv Papers. https://doi.org/10.31235/osf.io/yqt6n

Raudenbush, S., \& Eschmann, R. (2015). Does Schooling Increase or Reduce Social Inequality? Annual Review of Sociology, 41, 443-470.

Reardon, S. F. (2003). Sources of Inequality: The Growth of Racial/Ethnic and Socioeconomic Test Score Gaps in Kindergarten and First Grade. (Population Research Institute No. 03005). University Park, PA.

Reardon, S. F. (2011). The Widening Academic Achievement Gap Between the Rich and the Poor: New Evidence and Possible Explanations. Whither Opportunity? Rising Inequality and the Uncertain Life Chances of Low-Income Children, (July), 91-116.

Skopek, J., \& Passaretta, G. (2020, forthcoming). Socioeconomic Inequality in Children's Achievement from Infancy to Adolescence: The Case of Germany, Social Forces, 1-27. https://doi.org/10.1093/sf/soaa093

Shonkoff, J. P., \& Phillips, D. A. (2000). From Neurons to Neighborhoods: The Science of Early Childhood Development. Psykhe (Psykhe (Sa, Vol. 23). Washington, D.C.: National 
Academy Press.

Verachtert, P., Van Damme, J., Onghena, P., \& Ghesquière, P. (2009). A seasonal perspective on school effectiveness: Evidence from a Flemish longitudinal study in kindergarten and first grade. School Effectiveness and School Improvement, 20(2), 215-233.

von Hippel, P. T. (2016). From Kindergarten Through Second Grade, U.S. Children's Obesity Prevalence Grows Only During Summer Vacations. Obesity, 24(11), 2296-2300.

von Hippel, P. T. (2020). How will the coronavirus crisis affect children's learning? Unequally. von Hippel, P. T., \& Hamrock, C. (2019a). Do Test Score Gaps Grow before, during, or between the School Years? Measurement Artifacts and What We Can Know in Spite of Them. Sociological Science, 6, 43-80. https://doi.org/10.15195/v6.a3

von Hippel, P. T., \& Hamrock, C. (2019b). Do Test Score Gaps Grow before, during, or between the School Years? Measurement Artifacts and What We Can Know in Spite of Them. Sociological Science, 6, 43-80.

von Hippel, P. T., \& Hamrock, C. (2019c). Do Test Score Gaps Grow Before, During , or Between the School Years? Measurement Artifacts and What We Can Know in Spite of Them. Sociological Science, 6, 43-80.

von Hippel, P. T., Powell, B., Downey, D. B., \& Rowland, N. J. (2007). The effect of school on overweight in childhood: Gain in body mass index during the school year and during summer vacation. American Journal of Public Health, 97(4), 696-702.

von Hippel, P. T., Workman, J., \& Downey, D. B. (2018). Inequality in Reading and Math Skills Forms Mainly before Kindergarten: A Replication, and Partial Correction, of "Are Schools the Great Equalizer?" Sociology of Education, 91(4), 323-357. 


\section{TABLES}

Table 1. Overall analytical samples (boys and girls).

\begin{tabular}{|c|c|c|}
\hline Sample & $\mathrm{N}$ & Description \\
\hline Refreshment sample & 6,341 & Wave 3 - Grade 1 \\
\hline With parents' interviews & 5,660 & Not selective on SES \\
\hline List-wise deletion analytical variables & 5,481 & \\
\hline \multicolumn{3}{|l|}{ Compliers: } \\
\hline Sample A & 4,759 & $\begin{array}{l}\text { Children within the legally defined range } \\
\text { of birth dates at the cut-off }\end{array}$ \\
\hline \multicolumn{3}{|l|}{ Compliers without choice: } \\
\hline Sample B & 4,042 & $\begin{array}{l}\text { Excluded children at the lower and upper } \\
\text { limits of the legally defined range of birth } \\
\text { dates }\end{array}$ \\
\hline Sample C & 3,265 & $\begin{array}{l}\text { Excluded children at the lower }(+1 \text { month }) \\
\text { and upper ( }-1 \text { month) limits of the legally } \\
\text { defined range of birth dates }\end{array}$ \\
\hline
\end{tabular}


Table 2. Legal cut-off dates for mandatory schooling, school start, and definition of complier samples by federal state.

\begin{tabular}{|c|c|c|c|c|c|}
\hline $\begin{array}{l}\text { Federal state } \\
\text { (German 'Land') }\end{array}$ & $\begin{array}{l}\text { Legal cut- } \\
\text { off date }\end{array}$ & $\begin{array}{c}\text { Start of } \\
\text { school year } \\
2012 / 2013^{\text {b }} \\
\end{array}$ & $\begin{array}{l}\text { Compliers (Sample A) } \\
\text { born from/to }\end{array}$ & $\begin{array}{l}\text { Compliers (Sample B) } \\
\text { born from/to }\end{array}$ & $\begin{array}{l}\text { Compliers (Sample C) } \\
\text { born from/to }\end{array}$ \\
\hline Baden-Wuerttemberg & Sept. 30 & Sept. 10 & Oct. 2005 - Sept. 2006 & Nov. 2005 - Aug. 2006 & Dec. 2005 - July 2006 \\
\hline Bavaria & Sept. 30 & Sept. 13 & Oct. 2005 - Sept. 2006 & Nov. 2005 - Aug. 2006 & Dec. 2005 - July 2006 \\
\hline Berlin & Sept. 30 & Aug. 6 & Oct. 2005 - Sept. 2006 & Nov. 2005 - Aug. 2006 & Dec. 2005 - July 2006 \\
\hline Brandenburg & Sept. 30 & Aug. 6 & Oct. 2005 - Sept. 2006 & Nov. 2005 - Aug. 2006 & Dec. 2005 - July 2006 \\
\hline Bremen & June 30 & Sept. 3 & July 2005 - June 2006 & Aug. 2005 - May 2006 & Sept. 2005 - April 2006 \\
\hline Hamburg & June 30 & Aug. 2 & July 2005 - June 2006 & Aug. 2005 - May 2006 & Sept. 2005 - April 2006 \\
\hline Hesse & June 30 & Aug. 13 & July 2005 - June 2006 & Aug. 2005 - May 2006 & Sept. 2005 - April 2006 \\
\hline $\begin{array}{c}\text { Mecklenburg Western } \\
\text { Pomerania }\end{array}$ & June 30 & Aug. 6 & July 2005 - June 2006 & Aug. 2005 - May 2006 & Sept. 2005 - April 2006 \\
\hline Lower Saxony & Sept. 30 & Sept. 3 & Oct. 2005 - Sept. 2006 & Nov. 2005 - Aug. 2006 & Dec. 2005 - July 2006 \\
\hline $\begin{array}{l}\text { North Rhine- } \\
\text { Westphalia }\end{array}$ & Sept. 30 & Aug. 22 & Oct. 2005 - Sept. 2006 & Nov. 2005 - Aug. 2006 & Dec. 2005 - July 2006 \\
\hline Rhineland-Palatinate & Aug. 31 & Aug. 13 & Sept. 2005 - Aug. 2006 & Oct. 2005 - July 2006 & Nov. 2005 - June 2006 \\
\hline Saarland & June 30 & Aug. 15 & July 2005 - June 2006 & Aug. 2005 - May 2006 & Sept. 2005 - April 2006 \\
\hline Saxony & June 30 & Sept. 3 & July 2005 - June 2006 & Aug. 2005 - May 2006 & Sept. 2005 - April 2006 \\
\hline Saxony-Anhalt & June 30 & Sept. 6 & July 2005 - June 2006 & Aug. 2005 - May 2006 & Sept. 2005 - April 2006 \\
\hline Schleswig-Holstein & June 30 & Aug. 6 & July 2005 - June 2006 & Aug. 2005 - May 2006 & Sept. 2005 - April 2006 \\
\hline Thuringia & Aug. $1^{\mathrm{c}}$ & Sept. 3 & Aug. 2005 - July 2006 & Sept. 2005 - June 2006 & Oct. 2005 - May 2006 \\
\hline
\end{tabular}


Table 3. Sample distributions of analytical variables by sample.

\begin{tabular}{|c|c|c|c|c|c|c|c|c|c|c|c|c|}
\hline & \multicolumn{4}{|c|}{ Sample A $\left(N_{\max }=4,759\right)$} & \multicolumn{4}{|c|}{ Sample B $\left(N_{\max }=4,042\right)$} & \multicolumn{4}{|c|}{ Sample $\mathbf{C}\left(N_{\max }=3,265\right)$} \\
\hline & M & SD & $\min$ & $\max$ & M & SD & $\min$ & $\max$ & M & SD & $\min$ & $\max$ \\
\hline SES (years of parental education) & 14.1 & 2.2 & 8 & 18 & 14.1 & 2.2 & 8 & 18 & 14.1 & 2.2 & 8 & 18 \\
\hline Gender ( $1=$ male, $2=$ female $)$ & 1.5 & 0.5 & 1 & 2 & 1.5 & 0.5 & 1 & 2 & 1.5 & 0.5 & 1 & 2 \\
\hline Vocabulary & \multicolumn{4}{|c|}{$(N=4,503)$} & \multicolumn{4}{|c|}{$(N=3,827)$} & \multicolumn{4}{|c|}{$(N=3,083)$} \\
\hline Score (sum score) & 40.7 & 9.9 & 0.0 & 65.0 & 40.6 & 9.9 & 0.0 & 65.0 & 40.7 & 9.8 & 0.0 & 65.0 \\
\hline Age at test (months) & 85.0 & 3.8 & 77.1 & 95.1 & 85.0 & 3.4 & 78.1 & 94.1 & 84.9 & 2.9 & 79.1 & 93.0 \\
\hline School exposure (months) & 7.2 & 1.5 & 5.1 & 10.4 & 7.2 & 1.5 & 5.1 & 10.4 & 7.2 & 1.5 & 5.1 & 10.4 \\
\hline Grammar & \multicolumn{4}{|c|}{$(N=4,482)$} & \multicolumn{4}{|c|}{$(N=3,807)$} & \multicolumn{4}{|c|}{$(N=3,067)$} \\
\hline Score (WLE ${ }^{\mathrm{a}}$ score) & 1.8 & 1.2 & -4.6 & 5.9 & 1.8 & 1.2 & -4.6 & 5.9 & 1.8 & 1.2 & -4.6 & 5.9 \\
\hline Age at test (months) & 85.0 & 3.9 & 77.1 & 95.1 & 85.0 & 3.4 & 78.1 & 94.1 & 84.9 & 2.9 & 79.1 & 93.0 \\
\hline School exposure (months) & 7.2 & 1.5 & 5.1 & 10.4 & 7.2 & 1.5 & 5.1 & 10.4 & 7.2 & 1.5 & 5.1 & 10.4 \\
\hline Math & \multicolumn{4}{|c|}{$(N=4,529)$} & \multicolumn{4}{|c|}{$(N=3,847)$} & \multicolumn{4}{|c|}{$(N=3,108)$} \\
\hline Score (WLE ${ }^{\mathrm{a}}$ score) & 0.1 & 1.1 & -5.3 & 4.6 & 0.1 & 1.1 & -5.3 & 4.6 & 0.1 & 1.1 & -4.5 & 4.6 \\
\hline Age at test (months) & 85.0 & 3.8 & 77.1 & 95.1 & 84.9 & 3.3 & 78.1 & 94.1 & 84.9 & 2.9 & 79.1 & 93.0 \\
\hline School exposure (months) & 7.2 & 1.5 & 5.1 & 10.3 & 7.2 & 1.5 & 5.1 & 10.3 & 7.2 & 1.5 & 5.1 & 10.3 \\
\hline Science & \multicolumn{4}{|c|}{$(N=4,530)$} & \multicolumn{4}{|c|}{$(N=3,848)$} & \multicolumn{4}{|c|}{$(N=3,109)$} \\
\hline Score (WLE ${ }^{\mathrm{a}}$ score) & 0.1 & 0.9 & -2.8 & 4.1 & 0.1 & 0.9 & -2.8 & 3.6 & 0.1 & 0.9 & -2.8 & 3.6 \\
\hline Age at test (months) & 85.0 & 3.8 & 77.1 & 95.1 & 84.9 & 3.3 & 78.1 & 94.1 & 84.9 & 2.9 & 79.1 & 93.0 \\
\hline School exposure (months) & 7.2 & 1.5 & 5.1 & 10.3 & 7.2 & 1.5 & 5.1 & 10.3 & 7.2 & 1.5 & 5.1 & 10.3 \\
\hline
\end{tabular}

Notes: Full sample size $\left(N_{\max }\right)$ for complier samples A, B, and C. Outcome specific sub-samples $(N)$. Data weighted.

${ }^{a}$ Weighted Likelihood Estimation. 
Table 4. Regression of birth and test dates on parental SES and class level characteristics (coefficients and p-values).

\begin{tabular}{|c|c|c|c|c|c|c|}
\hline \multirow{2}{*}{$\begin{array}{r}\text { Outcome } \\
\text { Sample }\end{array}$} & \multicolumn{3}{|c|}{ Birth date } & \multicolumn{3}{|c|}{ Test date $^{\mathrm{a}}$} \\
\hline & A & B & $\mathrm{C}$ & $\mathrm{A}$ & B & $\mathrm{C}$ \\
\hline \multicolumn{7}{|l|}{ Student level } \\
\hline \multirow[t]{2}{*}{ Parental education } & 0.054 & 0.042 & 0.018 & -0.012 & -0.017 & -0.022 \\
\hline & .044 & .078 & 0.41 & 0.277 & .165 & .101 \\
\hline \multirow[t]{2}{*}{ Parental ISEI } & 0.005 & 0.001 & -0.001 & 0 & 0 & 0 \\
\hline & .087 & .61 & 0.757 & 0.896 & .769 & .844 \\
\hline \multicolumn{7}{|l|}{ Class level ${ }^{b}$} \\
\hline \multicolumn{7}{|l|}{ Social composition } \\
\hline \multirow[t]{2}{*}{$\%$ migrants } & 0 & -0.001 & -0.001 & -0.004 & -0.004 & -0.004 \\
\hline & .901 & .715 & .795 & .195 & .229 & .23 \\
\hline \multirow[t]{2}{*}{$\%$ low social class } & -0.006 & -0.006 & -0.003 & -0.004 & -0.004 & -0.003 \\
\hline & .18 & .172 & .327 & .259 & .298 & .405 \\
\hline \multirow[t]{2}{*}{$\%$ parents high educ. } & 0.004 & 0.008 & 0.006 & 0 & -0.001 & -0.001 \\
\hline & .423 & .054 & .08 & .941 & .834 & .81 \\
\hline \multicolumn{7}{|l|}{ Cognitive skills ${ }^{\mathrm{c}}$} \\
\hline \multirow[t]{2}{*}{ Written language } & -0.03 & 0.016 & -0.004 & 0.064 & 0.081 & 0.073 \\
\hline & .722 & .835 & .952 & .428 & .319 & .383 \\
\hline \multirow[t]{2}{*}{ Oral language } & 0.08 & 0.103 & 0.012 & 0.028 & 0.026 & 0.026 \\
\hline & .328 & .176 & .855 & .736 & .757 & .765 \\
\hline \multirow[t]{2}{*}{ Science } & 0.073 & 0.038 & -0.034 & 0.033 & 0.029 & 0.042 \\
\hline & .388 & .635 & .628 & .718 & .755 & .66 \\
\hline \multirow[t]{2}{*}{ Math } & 0.056 & 0.071 & -0.018 & 0.045 & 0.035 & 0.037 \\
\hline & .583 & .453 & .825 & .645 & .723 & .713 \\
\hline \multicolumn{7}{|l|}{ Non-cognitive skills } \\
\hline \multirow[t]{2}{*}{ Social skills ${ }^{c}$} & 0.058 & 0.11 & 0.092 & -0.073 & -0.092 & -0.093 \\
\hline & .447 & .115 & .164 & .368 & .247 & .261 \\
\hline \multirow[t]{2}{*}{ Interested ${ }^{\mathrm{d}}$} & -0.022 & 0.039 & 0.05 & 0.019 & 0.002 & -0.008 \\
\hline & .808 & .651 & .543 & .854 & .987 & .94 \\
\hline \multirow{2}{*}{ Autonomous ${ }^{\mathrm{d}}$} & 0.08 & 0.106 & 0.107 & 0.047 & 0.024 & 0.032 \\
\hline & .364 & .202 & .179 & .603 & .786 & .72 \\
\hline \multirow[t]{2}{*}{ Concentrated $^{\mathrm{d}}$} & 0.028 & 0.034 & 0.035 & -0.115 & -0.129 & -0.133 \\
\hline & .742 & .673 & .638 & .225 & .171 & .174 \\
\hline \multirow[t]{2}{*}{ Classroom size $\left(\mathrm{m}^{2}\right)^{\mathrm{e}}$} & -0.008 & 0.012 & 0.04 & -0.002 & -0.01 & -0.016 \\
\hline & .884 & .818 & .394 & .972 & .865 & .798 \\
\hline \multicolumn{7}{|l|}{ Quality of classroom ${ }^{\mathrm{f}}$} \\
\hline Brightness & -0.041 & -0.038 & -0.063 & -0.135 & -0.11 & -0.101 \\
\hline & .655 & .646 & .402 & .148 & .243 & .294 \\
\hline Size & 0.005 & 0.009 & 0.07 & -0.1 & -0.093 & -0.077 \\
\hline & .931 & .877 & .149 & .18 & .203 & .295 \\
\hline Functionality & 0.038 & 0.071 & 0.056 & -0.065 & -0.068 & -0.052 \\
\hline & .592 & .312 & .348 & .452 & .432 & .556 \\
\hline Structural integrity & 0 & 0.02 & -0.013 & 0.014 & -0.003 & 0.005 \\
\hline & .999 & .756 & .822 & .856 & .965 & .95 \\
\hline Acoustics & -0.1 & -0.089 & -0.041 & -0.081 & -0.055 & -0.043 \\
\hline & .118 & .158 & .471 & .33 & .504 & .602 \\
\hline
\end{tabular}

Notes: Coefficients and p-values from 114 separate linear regression models predicting test dates and birth dates by Samples A, B, and C. All models control for federal state fixed effects (coefficients not shown). Number of observations for each model changes as to maximize sample size. Data weighted. ${ }^{a}$ First test date shown (second test date in Supplementary Table B1). ${ }^{\mathrm{b}}$ Teacher's evaluation of the students in class. Standard errors clustered by class. ${ }^{c} 5$-point scaled from much worse (1) to much better (5) compared to curriculum expectations. ${ }^{\mathrm{d}}$ 5-point semantic differential: uninterested to interested, not autonomous to autonomous, not concentrated to concentrated. ${ }^{\mathrm{e}}$ Square meters size of the classroom: 5 categories ranging from under 30 (1) to 60 and more (5). ${ }^{\mathrm{f}}$ Classroom quality and condition; each 4-point scale from poor (1) to good (4). 
Table 5. The effects of parental education (SES), age at test day and school exposure at test day on standardized test scores (Sample A boys and girls jointly).

\begin{tabular}{|c|c|c|c|c|c|c|c|c|c|c|c|c|}
\hline & \multicolumn{6}{|c|}{ Baseline models (Equation 5) } & \multicolumn{6}{|c|}{ Models with interaction terms (Equation 6) } \\
\hline & \multirow{2}{*}{ Vocab. } & \multirow{2}{*}{ Gram. } & \multicolumn{2}{|c|}{ Math } & \multicolumn{2}{|c|}{ Science } & \multirow{2}{*}{ Vocab. } & \multirow{2}{*}{ Gram. } & \multicolumn{2}{|c|}{ Math } & \multicolumn{2}{|c|}{ Science } \\
\hline & & & Unadj. & Rel-adj. & Unadj. & Rel-adj. & & & Unadj. & Rel-adj. & Unadj. & Rel-adj. \\
\hline \multirow[t]{2}{*}{ SES } & 0.181 & 0.184 & 0.154 & 0.180 & 0.171 & 0.200 & 0.181 & 0.185 & 0.155 & 0.180 & 0.172 & 0.202 \\
\hline & .000 & .000 & .000 & .000 & .000 & .000 & .000 & .000 & .000 & .000 & .000 & .000 \\
\hline \multirow[t]{2}{*}{ School exp. } & 0.029 & 0.033 & 0.117 & 0.136 & 0.094 & 0.111 & 0.029 & 0.032 & 0.117 & 0.136 & 0.093 & 0.109 \\
\hline & .019 & .008 & .000 & .000 & .000 & .000 & .019 & .009 & .000 & .000 & .000 & .000 \\
\hline \multirow[t]{2}{*}{ SES $\times$ School exp } & & & & & & & 0.002 & 0.008 & -0.002 & -0.003 & 0.003 & 0.004 \\
\hline & & & & & & & .675 & .159 & .666 & .666 & .559 & .559 \\
\hline \multirow[t]{2}{*}{ Age (at test day) } & 0.044 & 0.029 & 0.039 & 0.046 & 0.037 & 0.044 & 0.044 & 0.029 & 0.040 & 0.046 & 0.038 & 0.044 \\
\hline & .000 & .000 & .000 & .000 & .000 & .000 & .000 & .000 & .000 & .000 & .000 & .000 \\
\hline \multirow[t]{2}{*}{ SES $\times$ Age } & & & & & & & -0.001 & -0.001 & 0.004 & 0.004 & 0.007 & 0.008 \\
\hline & & & & & & & .563 & .574 & .059 & .059 & .005 & .005 \\
\hline \multirow[t]{2}{*}{ Constant } & 0.040 & -0.086 & 0.093 & 0.108 & 0.017 & 0.020 & 0.040 & -0.086 & 0.094 & 0.110 & 0.019 & 0.023 \\
\hline & .090 & .000 & .000 & .000 & .483 & .483 & .093 & .000 & .000 & .000 & .427 & .427 \\
\hline $\mathrm{N}$ & 503 & 4482 & 4529 & 4529 & 4530 & 4530 & 4503 & 4482 & 4529 & 4529 & 4530 & 4530 \\
\hline$R^{2}$ & .229 & .222 & .216 & .216 & .214 & .214 & .229 & .223 & .217 & .217 & .217 & .217 \\
\hline
\end{tabular}

Notes: Fixed effects regression models on z-standardized test score outcomes in vocabulary, grammar, math (unadjusted and adjusted for score reliability), and science (unadjusted and adjusted for score reliability). All estimations on Sample A. Coefficients and p-values shown. Fixed effects specification accounts for heterogeneity by federal states. SES (years of parental education), age at test day and school exposure at test day (both months) are centered at the mean. All models control for gender (female dummy). 


\section{FIGURES}

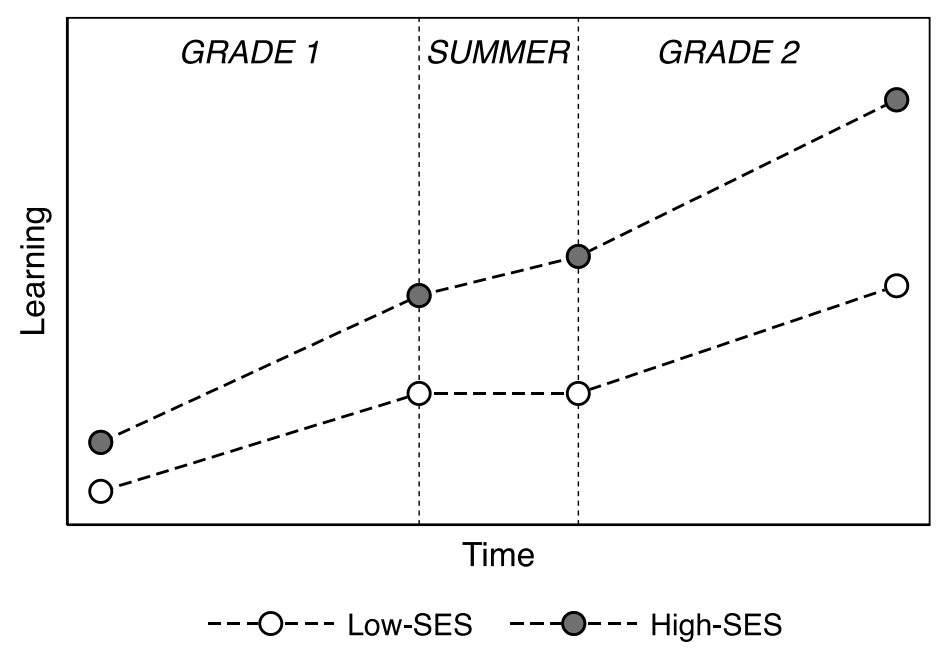

Figure 1. Seasonal Comparison Design: SES inequality increases faster over the summer compared to the school years. 

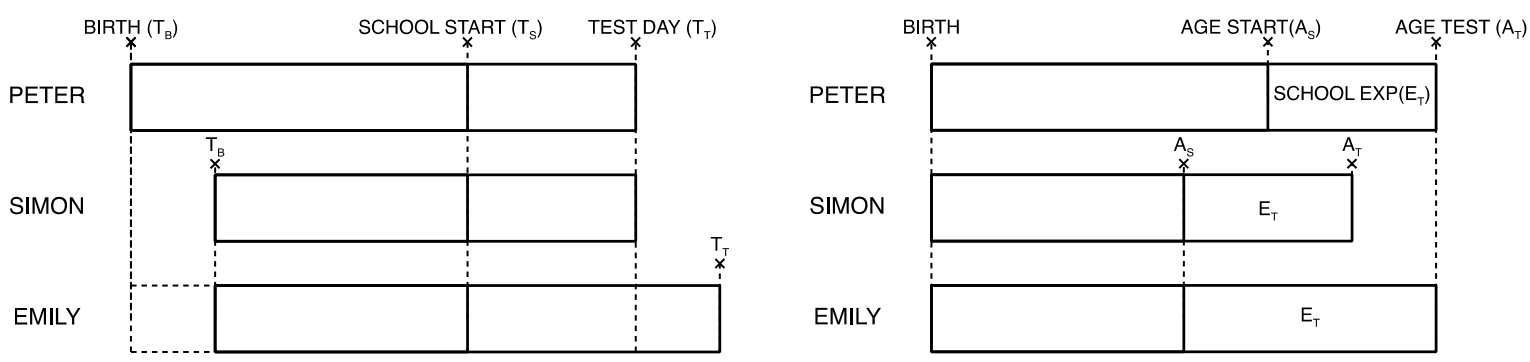

\begin{tabular}{|c|c|c|c|c|c|c|c|c|c|}
\hline & \multicolumn{3}{|c|}{ Panel A: Calendar time } & \multicolumn{3}{|c|}{ Panel B: Chronological age } & \multicolumn{3}{|c|}{ Comparisons } \\
\hline & $\begin{array}{l}\text { Birth } \\
\left(T_{b}\right)\end{array}$ & $\begin{array}{c}\text { School start } \\
\left(T_{\mathrm{s}}\right)\end{array}$ & $\begin{array}{l}\text { Test } \\
\left(T_{t}\right)\end{array}$ & $\begin{array}{l}\text { Age entry } \\
\left(A_{s}\right)\end{array}$ & $\begin{array}{l}\text { Exp. test } \\
\left(E_{t}\right)\end{array}$ & $\begin{array}{c}\text { Age test } \\
\left(A_{t}\right)\end{array}$ & $\begin{array}{c}\text { Test } \\
\text { score }\end{array}$ & $\begin{array}{l}=E_{t} \\
\Delta A_{t}\end{array}$ & $\begin{array}{l}\Delta \mathrm{E}_{\mathrm{t}} \\
=\mathrm{A}_{\mathrm{t}}\end{array}$ \\
\hline PETER & $2006 / 8$ & $2012 / 8$ & $2013 / 2$ & 72 & 6 & 78 & 100 & $x$ & $x$ \\
\hline SIMON & $2006 / 11$ & $2012 / 8$ & $2013 / 2$ & 69 & 6 & 75 & 90 & $x$ & \\
\hline EMILY & $2006 / 11$ & $2012 / 8$ & $2013 / 5$ & 69 & 9 & 78 & 110 & & $x$ \\
\hline
\end{tabular}

Figure 2. Illustration of the core elements of our design. Peter-Simon: same school exposure but different age at test day. Peter-Emily: Same age but different school exposure at test day. 



Figure 3. The effects of SES (parental education) and school exposure ('exp') at test day on cognitive achievement. Compliers sample (A) and more restricted samples of compliers without choice (B and C). Overall sample (upper panel), boys (middle panel) and girls (lower panel). 


\section{APPENDIX}

\section{A. COMPOSITE EXPOSURE EFFECT ON SES-INEQUALITY: DEMONSTRATION}

Imagine a theoretical model in which age at test day $\left(A_{t}\right)$, age at entry $\left(A_{s}\right)$, and school-year exposure $\left(E_{t}\right)$ have separate SES-specific effects on achievement:

$$
\begin{aligned}
y=\gamma_{0}+ & \gamma_{1} A_{t}+\gamma_{2} A_{s}+\gamma_{3} E_{t}+\delta_{0} S E S+\delta_{1}\left(S E S \cdot A_{t}\right)+\delta_{2}\left(S E S \cdot A_{s}\right) \\
& +\delta_{3}\left(S E S \cdot E_{t}\right)
\end{aligned}
$$

Rearranging the terms in Eq. A1 we obtain:

$$
y=\gamma_{0}+\left(\gamma_{1}+\delta_{1} S E S\right) A_{t}+\left(\gamma_{2}+\delta_{2} S E S\right) A_{s}+\left(\gamma_{3}+\delta_{3} S E S\right) E_{t}+\delta_{0} S E S
$$

Replacing $A_{s}$ with $A_{s}=A_{t}-E_{t}$ (remember that $E_{t}=T_{t}-T_{s}, A_{t}=T_{t}-T_{b}$, and $A_{s}=T_{s}-$ $T_{b}$ ) and rearranging terms in Eq. A2 leads to:

$$
\begin{aligned}
y=\gamma_{0}+ & \left(\gamma_{1}+\delta_{1} S E S\right) A_{t}+\left(\gamma_{2}+\delta_{2} S E S\right) \cdot\left(A_{t}-E_{t}\right)+\left(\gamma_{3}+\delta_{3} S E S\right) E_{t} \\
& +\delta_{0} S E S
\end{aligned}
$$

Corresponding to:

$$
\begin{aligned}
y=\gamma_{0}+ & \left(\gamma_{1}+\delta_{1} S E S+\gamma_{2}+\delta_{2} S E S\right) A_{t}+\left(\gamma_{3}+\delta_{3} S E S-\gamma_{2}-\delta_{2} S E S\right) E_{t} \\
& +\delta_{0} S E S
\end{aligned}
$$

and

$$
\begin{aligned}
y=\gamma_{0}+\{ & \left.\left.\left(\gamma_{1}+\gamma_{2}\right)+\left(\delta_{1}+\delta_{2}\right) S E S\right)\right\} A_{t}+\left\{\left(\gamma_{3}-\gamma_{2}\right)+\left(\delta_{3}-\delta_{2}\right) S E S\right\} E_{t} \\
& +\delta_{0} S E S
\end{aligned}
$$

Equation A4 makes it clear that the school exposure effect we estimate is a function of (1) the difference in the main effects of the school exposure and age of entry $\left(\gamma_{3}-\gamma_{2}\right)$, (2) the level of SES, and (3) the difference of the interaction effects between school exposure and SES and age of entry and SES, respectively $\left(\delta_{3}-\delta_{2}\right)$. 
When we focus on SES-gradients in our model, we obtain:

$$
\frac{\delta y}{\delta S E S}=\delta_{0}+\left(\delta_{1}+\delta_{2}\right) \cdot A_{t}+\left(\delta_{3}-\delta_{2}\right) \cdot E_{t}
$$

If we increase school exposure, the estimated SES gradient is:

$$
\frac{\delta y}{\delta S E S \delta E_{t}}=\delta_{3}-\delta_{2}
$$




\section{B. EXOGENEITY OF THE TREATMENT: SECOND TEST DATE}

Table B1. Children's parental SES and class-level characteristics as predictors of the second test date. Coefficients and p-values $(95 \%)$.

\begin{tabular}{|c|c|c|c|}
\hline \multirow[b]{2}{*}{ Sample } & \multicolumn{3}{|c|}{ Second test date } \\
\hline & A & B & $\mathrm{C}$ \\
\hline \multicolumn{4}{|l|}{ Student level } \\
\hline Parental education & $\begin{array}{c}-0.015 \\
.18\end{array}$ & $\begin{array}{c}-0.021 \\
.08\end{array}$ & $\begin{array}{c}-0.027 \\
.05\end{array}$ \\
\hline \multirow[t]{2}{*}{ Parental ISEI } & -0.001 & -0.001 & -0.001 \\
\hline & .625 & .623 & .382 \\
\hline \multicolumn{4}{|l|}{ Class level $^{\mathrm{a}}$} \\
\hline \multicolumn{4}{|l|}{ Social composition } \\
\hline \multirow[t]{2}{*}{$\%$ migrants } & -0.004 & -0.004 & -0.005 \\
\hline & .155 & .18 & .157 \\
\hline \multirow[t]{2}{*}{$\%$ low social class } & -0.005 & -0.005 & -0.005 \\
\hline & .154 & .148 & .179 \\
\hline \multirow{2}{*}{$\%$ parents high educ. } & 0 & 0 & 0 \\
\hline & .922 & .924 & .926 \\
\hline \multicolumn{4}{|l|}{ Cognitive skills ${ }^{b}$} \\
\hline \multirow{2}{*}{ Written language } & .085 & 0.104 & 0.098 \\
\hline & 0.296 & .206 & .254 \\
\hline \multirow[t]{2}{*}{ Oral language } & .014 & 0.012 & 0.014 \\
\hline & 0.871 & .891 & .885 \\
\hline \multirow[t]{2}{*}{ Science } & .037 & 0.034 & 0.052 \\
\hline & 0.676 & .71 & .581 \\
\hline \multirow[t]{2}{*}{ Math } & .054 & 0.051 & 0.053 \\
\hline & 0.579 & .602 & .599 \\
\hline \multicolumn{4}{|l|}{ Non-cognitive skills } \\
\hline \multirow{2}{*}{ Social skills ${ }^{b}$} & -0.033 & -0.052 & -0.056 \\
\hline & .677 & .527 & .514 \\
\hline \multirow{2}{*}{ Interested $^{c}$} & 0.028 & 0.014 & 0.007 \\
\hline & .796 & .897 & .952 \\
\hline \multirow[t]{2}{*}{ Autonomous ${ }^{\mathrm{c}}$} & 0.071 & 0.054 & 0.067 \\
\hline & .419 & .544 & .451 \\
\hline \multirow[t]{2}{*}{ Concentrated $^{c}$} & -0.086 & -0.099 & -0.089 \\
\hline & .327 & .275 & .337 \\
\hline \multirow[t]{2}{*}{ Classroom size $\left(\mathrm{m}^{2}\right)^{\mathrm{d}}$} & 0.007 & -0.003 & -0.013 \\
\hline & .912 & .967 & .834 \\
\hline \multicolumn{4}{|l|}{ Quality of classroom ${ }^{\mathrm{e}}$} \\
\hline \multirow[t]{2}{*}{ Brightness } & -0.167 & -0.144 & -0.133 \\
\hline & .08 & .143 & .183 \\
\hline \multirow[t]{2}{*}{ Size } & -0.127 & -0.125 & -0.114 \\
\hline & .081 & .087 & .125 \\
\hline \multirow[t]{2}{*}{ Functionality } & -0.101 & -0.106 & -0.093 \\
\hline & .232 & .219 & .299 \\
\hline Structural integrity & -0.037 & -0.053 & -0.04 \\
\hline & .622 & .48 & .599 \\
\hline Acoustics & -0.097 & -0.074 & -0.056 \\
\hline & .232 & .36 & .494 \\
\hline
\end{tabular}

Notes: Coefficients and p-values from 114 linear regression models predicting test dates and birth dates by Samples A, B, and C. All models control for federal state fixed effects (coefficients not shown). Number of observations for each model changes as to maximize sample size. Data weighted. a Teacher's evaluation of the students in class. Standard errors clustered by class. ${ }^{\mathrm{b}}$ 5-point scaled from much 
worse (1) to much better (5) compared to curriculum expectations. ${ }^{\mathrm{c}}$ 5-point semantic differential: uninterested to interested, not autonomous to autonomous, not concentrated to concentrated. ${ }^{\mathrm{d}}$ Square meters size of the classroom: 5 categories ranging from under 30 (1) to 60 and more (5). ${ }^{\text {e }}$ Classroom quality and condition; each 4point scale from poor (1) to good (4). 


\section{AdDitional Figures: MAIN ANALYSES}
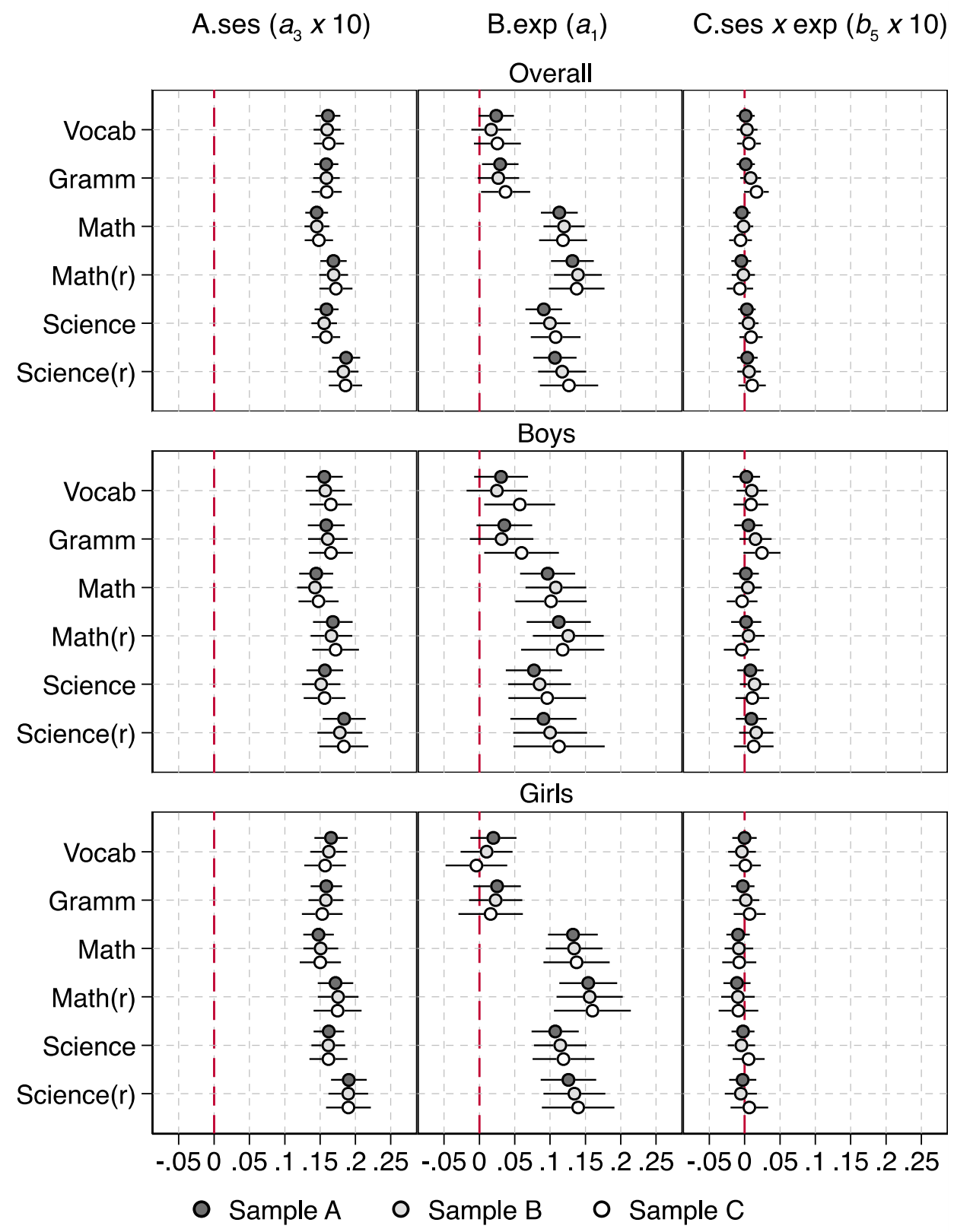

Figure C1. The effects of SES (parental ISEI) and school exposure ('exp') at test day on cognitive achievement. Compliers sample (A) and more restricted samples of compliers without choice (B and C). Overall sample (upper panel), boys (middle panel) and girls (lower panel). 


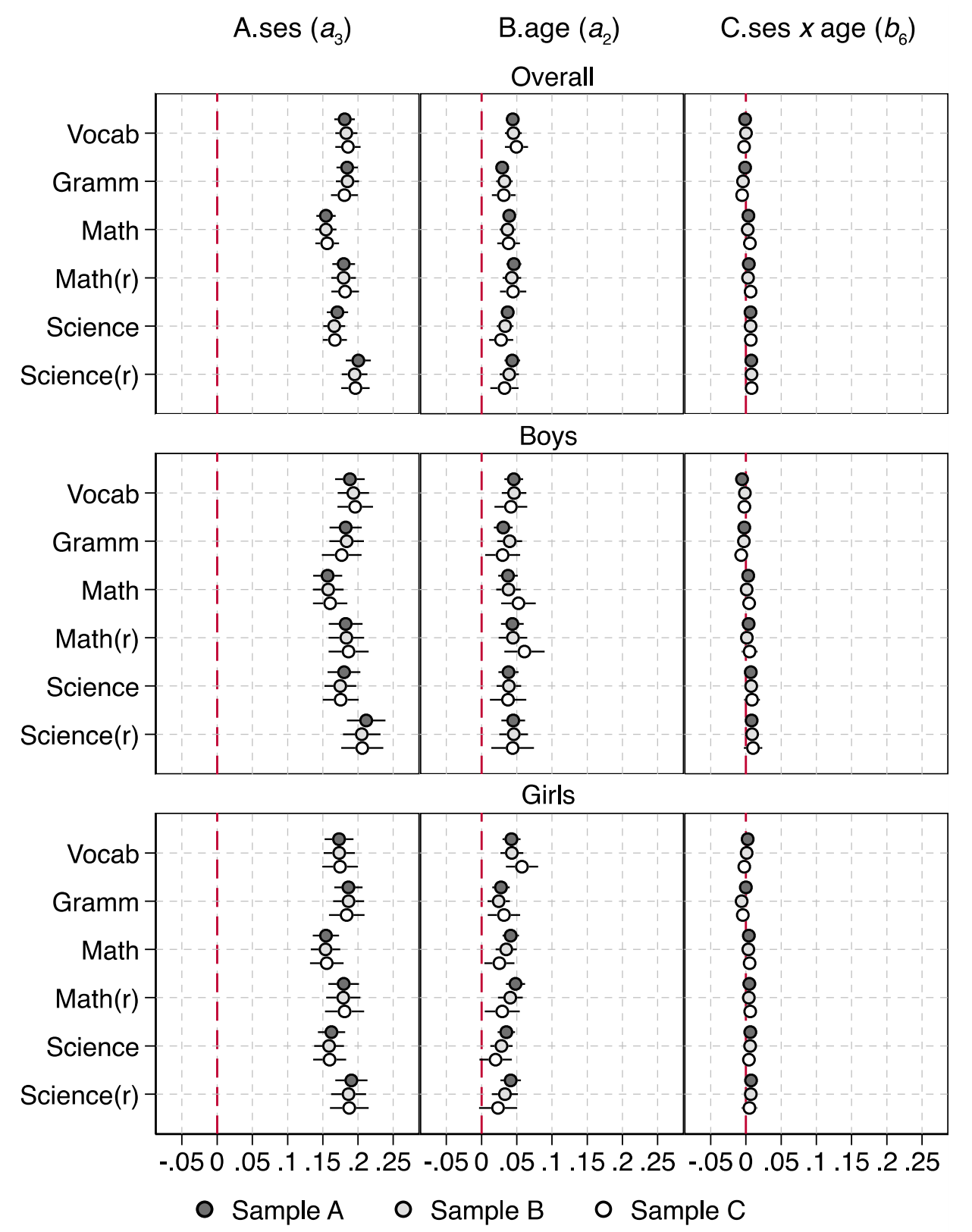

Figure $\mathrm{C} 2$. The effects of SES (parental education) and age at test on cognitive achievement. Compliers sample (A) and more restricted samples of compliers without choice (B and C). Overall sample (upper panel), boys (middle panel) and girls (lower panel). 


\section{ROBUSTNESS ANALYSES}


Figure D1. Controlling for migration background. The effects parental education and school exposure ('exp') at test day on cognitive achievement. Compliers sample (A) and more restricted samples of compliers without choice (B and C). Overall sample (upper panel), boys (middle panel) and girls (lower panel). 

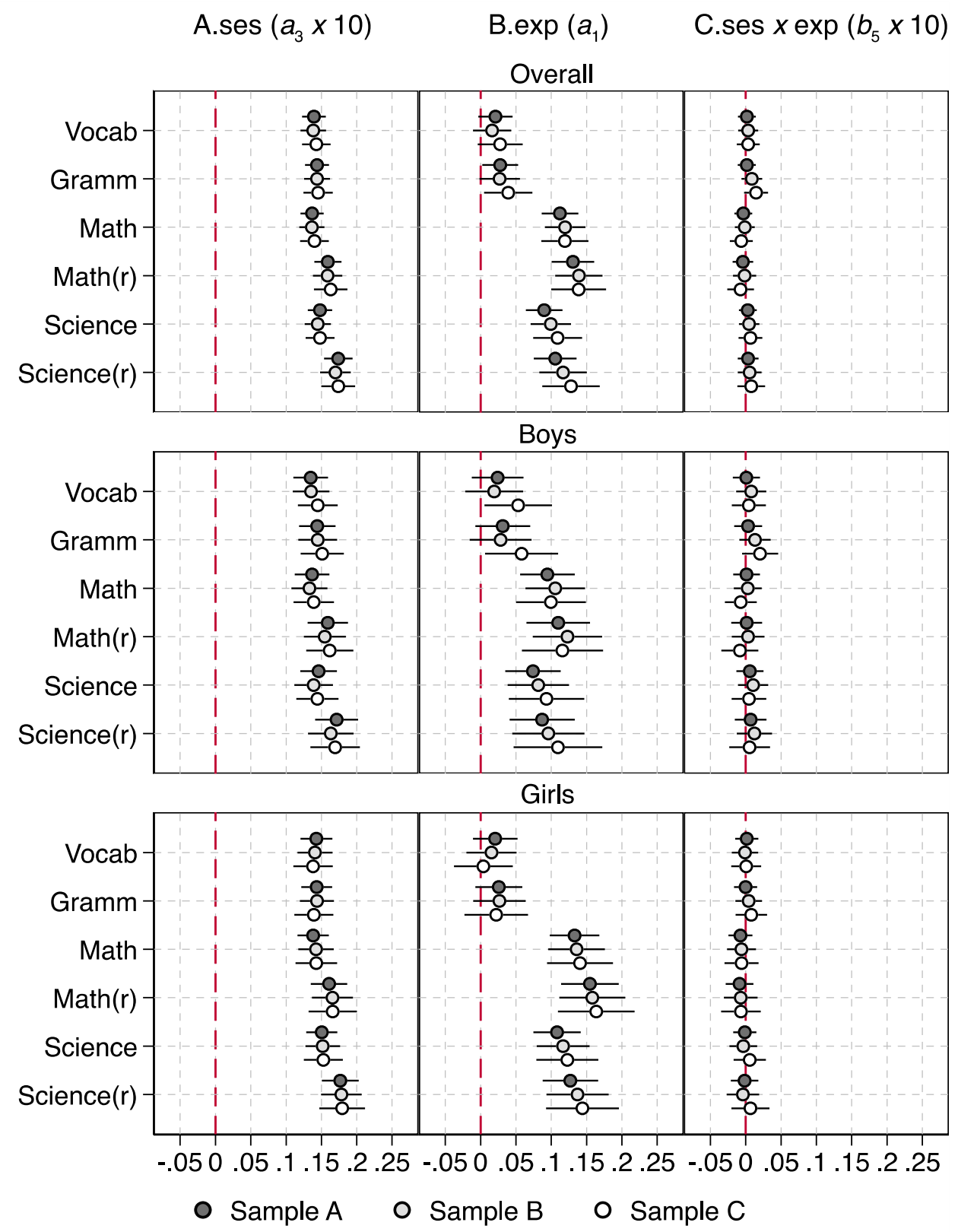

Figure D2. Controlling for migration background. The effects parental ISEI and school exposure ('exp') at test day on cognitive achievement. Compliers sample (A) and more restricted samples of compliers without choice (B and C). Overall sample (upper panel), boys (middle panel) and girls (lower panel). 


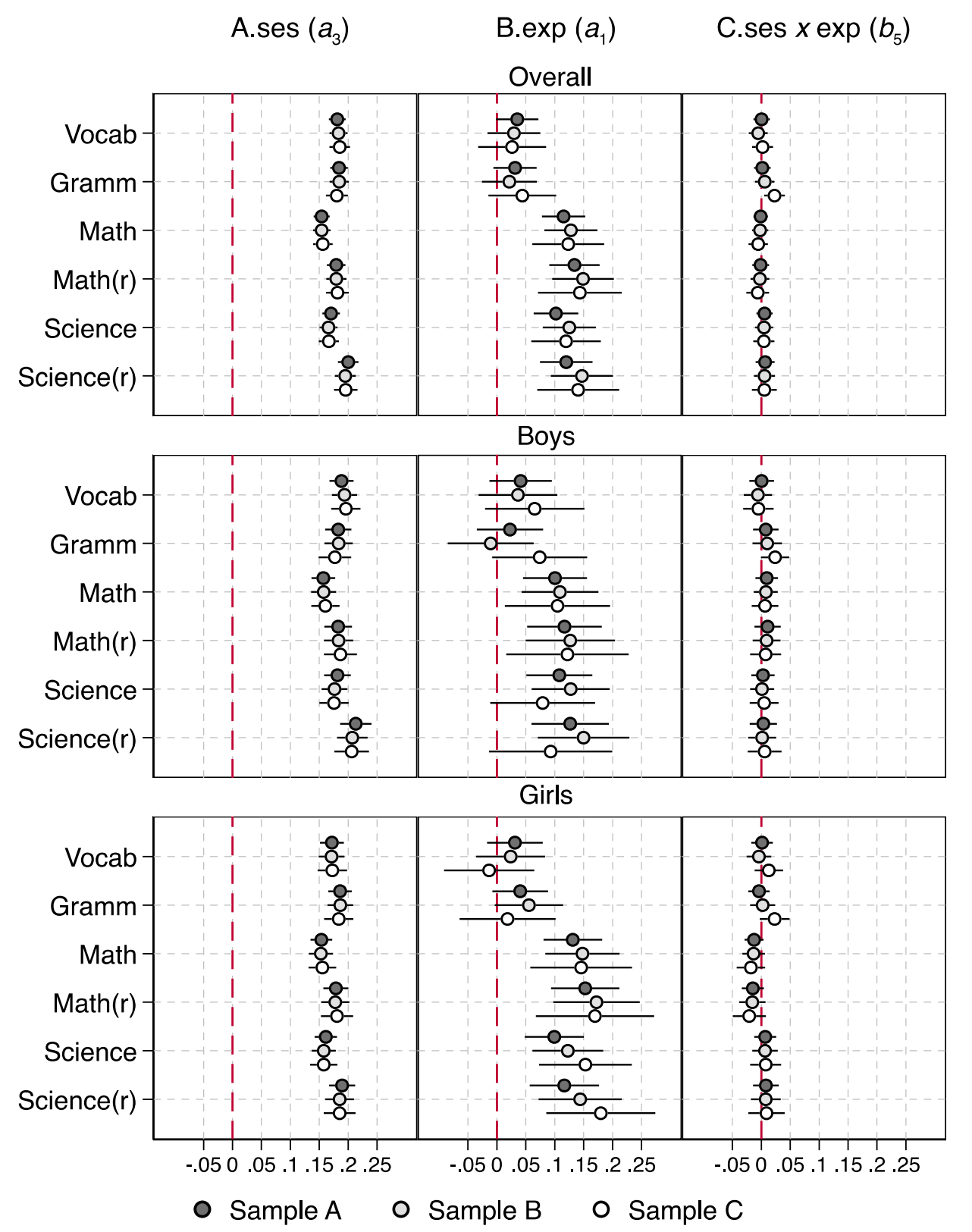

Figure D3. Controlling for entry age dummies. The effects of parental education and school exposure ('exp') at test day on cognitive achievement. Compliers sample (A) and more restricted samples of compliers without choice (B and C). Overall sample (upper panel), boys (middle panel) and girls (lower panel). 


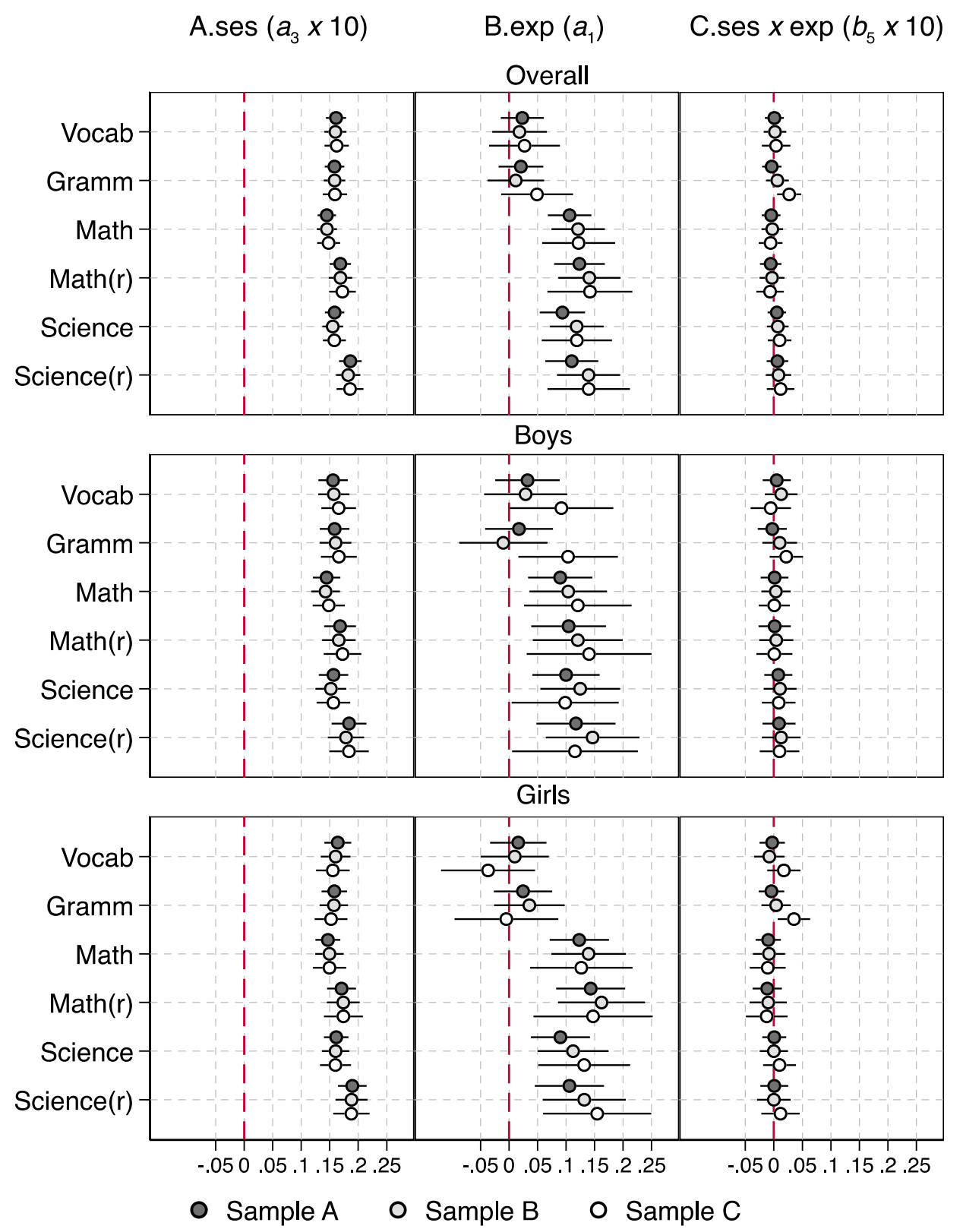

Figure D4. Controlling for entry age dummies. The effects of parental ISEI and school exposure ('exp') at test day on cognitive achievement. Compliers sample (A) and more restricted samples of compliers without choice (B and C). Overall sample (upper panel), boys (middle panel) and girls (lower panel). 